\title{
Experimental investigation of spray characteristics of ethyl esters in a constant volume chamber
}

\author{
Anılcan Ulu ${ }^{1}\left[\right.$ ] $\cdot$ Güray Yildiz ${ }^{2}$ Ünver Özkol ${ }^{1}$. Alvaro Diez Rodriguez ${ }^{1}$
}

Received: 30 November 2021 / Revised: 7 February 2022 / Accepted: 15 February 2022

(c) The Author(s), under exclusive licence to Springer-Verlag GmbH Germany, part of Springer Nature 2022

\begin{abstract}
Biodiesels are mainly produced via the utilization of methanol in transesterification, which is the widespread biodiesel production process. The majority of this methanol is currently obtained from fossil resources, i.e. coal and natural gas. However, in contrast with methanol, biomass-based ethanol can also be used to produce biodiesels; this could allow the production line to become fully renewable. This study aimed to investigate the spray characteristics of various ethyl ester type biodiesels derived from sunflower and corn oils in comparison to methyl esters based on the same feedstocks and reference petroleum-based diesel. Spray penetration length (SPL) and spray cone angle (SCA) were experimentally evaluated in a constant volume chamber allowing optical access, under chamber pressures of $0,5,10$ and 15 bar and injection pressures of 600 and 800 bar. Sauter mean diameter (SMD) values were estimated by using an analytical correlation. Consequently, ethyl esters performed longer SPL (2.8-20\%) and narrower SCA (5.1-19\%) than diesel under ambient pressures of 5 and 10 bar. Although the SMD values of ethyl esters were $48 \%$ higher than diesel on average, their macroscopic spray characteristics were very similar to those of diesel under 15 bar chamber pressure. Moreover, ethyl esters were found to be very similar to methyl esters in terms of spray characteristics. The differences in SPL, SCA and SMD values for both types of biodiesels were lower than $4 \%$. When considering the uncertainty $( \pm 0.84 \%)$ and repeatability $( \pm 5 \%)$ ratios, the difference between the spray characteristics of methyl and ethyl esters was not major.
\end{abstract}

Keywords Biodiesel $\cdot$ Ethyl ester $\cdot$ Methyl ester $\cdot$ Spray investigation $\cdot$ Constant volume chamber

\section{Statement of Novelty \\ Methanol obtained from fossil resources is the most widespread alcohol utilized in biodiesel production process. In contrast, ethanol is produced from biogenic resources like maize, sugarcane, etc. Thus, biodiesel can be fully renewable if ethanol is used instead of methanol in the biodiesel production process. Besides, ethyl esters have extra advantages over methyl esters such that they can have better performances in cold weather. However, studies considering the characteristics of ethyl esters are limited in the literature, and these papers have fully focused on performance and emission characteristics. Any published paper investigating the spray characteristics of ethyl esters is not yet available. This paper brings a certain novelty by investigating the spray characteristics of various ethyl ester type biodiesels.}

Anılcan Ulu

anilcanulu@iyte.edu.tr; anilcanulu057@gmail.com

1 Department of Mechanical Engineering, İzmir Institute of Technology, Faculty of Engineering, Urla, 35430 İzmir, Turkey

2 Department of Energy Systems Engineering, İzmir Institute of Technology, Faculty of Engineering, Urla, 35430 İzmir, Turkey

\section{Introduction}

Conventional diesel fuel (petrodiesel) consumption has been one of the major sources of air pollution. As a result of petrodiesel combustion, various toxic gases, e.g. carbon monoxide $(\mathrm{CO})$, hydrocarbons $(\mathrm{HC})$, nitric oxides $\left(\mathrm{NO}_{\mathrm{x}}\right)$ and particulate matters (PM) are emitted to the atmosphere [1]. These pollutants contribute to serious environmental problems, as global warming is considered to be the most serious one for the planet. Hence, to mitigate such pollutant emissions, it is necessary to increase the share of alternative fuels that can directly be utilized in diesel engines. In this context, the major emerging alternative fuel for use in conventional diesel engines is biodiesel [2, 3]. Biodiesels are promising fuels addressing the aforementioned environmental concerns since they are renewable and biodegradable [4-6], reducing the harmful emissions [7-9] and having the ability to directly be utilized in existing diesel engines with little or no modifications [10, 11]. In 2019, total global biodiesel consumption was almost 104 thousand tonnes $\bullet$ day $^{-1}$ 
[12]. However, this value remains low compared to that of the petrodiesel consumption, where it was $c a .3746$ thousand tonnes $\bullet d_{a y}{ }^{-1}[12]$. These figures yield a biodiesel to petrodiesel consumption ratio of approximately $3 \%$. Although it is obvious that biodiesel has not yet completely replaced petrodiesel, scientific and industrial interest continues to increase concerning the use and utilization of biodiesel. Correspondingly, the search for new feedstocks for biodiesel production is ongoing [13-15], and improvements in biodiesel production technologies continue to be an important research focus $[16,17]$. Moreover, the effects of biodiesel on diesel engines in terms of their performance and emission levels continue to be examined $[18,19]$. These efforts clearly show that biodiesel maintains its importance.

Biodiesel is a term generally used for drop-in renewable biofuels produced via the transesterification technique. Transesterification is a simple, cheap and hence, a widespread process [11], where various types of biogenic feedstocks, e.g. of vegetable oils, animal fats, algal and/or waste cooking oils [10] can be utilized for the production of biodiesel. Biodiesel fuels can be first, second or third generation according to the feedstock type and whether the feedstock is sustainable or not. For instance, corn oil, waste cooking oil and algal oil are examples of the resources for the first, second and third-generation biodiesels, respectively [11]. In the transesterification process, the oil from which the fuel will be produced is combined with alcohol with the help of a catalyst [20]. Various alcohols can be used in this process; however, due to its low cost and wide availability, methanol is the most widely used one for biodiesel production [21, 22].

Since methanol is largely fossil-based, biodiesel derived via the utilization of methanol is not completely renewable [23]. In 2019, 123.36 billion litres of methanol were produced globally, and approximately $65 \%$ and $35 \%$ of methanol were respectively produced from natural gas and coal [24]. The amount of methanol produced from renewable energy sources was less than 1\% [24]. In contrast, 109.89 billion litres of ethanol were produced in the world in 2019 [25]. Although ethanol production decreased globally almost by $15 \%$ in 2020 due to the COVID-19 outbreak [26], the production amount was still significant. In 2020, most of the ethanol was produced from maize ( $c a .64 \%)$, and different feedstocks such as sugarcane (26\%), molasses (3\%), wheat (3\%) and other grains, cassava or sugar beets, were also utilized [27]. For this reason, bio-based ethanol could be considered as an alternative for fossil-based methanol; this ensures that the resulting biodiesel is fully renewable. Biodiesels obtained via the utilization of methanol or ethanol in the transesterification process are respectively named methyl and ethyl esters. Ethyl esters have some considerable advantages over methyl esters, such as having lower iodine values, higher oxidation stabilities and better lubricity characteristics [21, 22]. As an important superiority, cloud, cold filter plugging and pour points of ethyl esters are also lower than those of methyl esters, making their cold flow properties better than that of the methyl esters [28, 29]. These advantages show that the use of bio-based ethanol in biodiesel production can be beneficial for their use in diesel engines.

Despite their superiority and aforementioned advantages, published research studies concerning ethyl esters in terms of their use in diesel engines are limited compared to that of methyl esters. However, when considering performance and emission analysis according to existing research [30-38], ethyl esters could be considered as clear alternatives. Table 1 shows the existing literature studies, where the performance and emission characteristics of ethyl esters are compared with that of methyl esters. The table also compares some important physical and chemical properties like calorific values, viscosities and densities of both. For example, Sanli et al. [30] investigated the performance and emission characteristics of waste frying oil (WFO)-based ethyl ester and methyl ester biodiesels in a six-cylinder, four-stroke, water-cooled, turbocharged diesel engine. Differences between the physical and chemical properties of these fuels were minor. Ethyl ester had a $0.1 \%$ smaller density, $8.9 \%$ larger viscosity and $0.58 \%$ higher calorific value than methyl ester. When comparing the performance characteristics of these fuels, it was observed that ethyl ester performed a $2.38 \%$ reduction in brake specific fuel consumption and $1.98 \%$ advancement in brake thermal efficiency on average. For emission analysis, they found that ethyl ester emitted $8 \%$ less $\mathrm{CO}$ and $12.7 \%$ less $\mathrm{HC}$ on average than methyl ester, and $\mathrm{NO}_{\mathrm{x}}$ emissions were very close to each other for both fuels. The authors of the study explained that ethyl ester had slightly better results in terms of performance and emission characteristics than methyl ester originated from the same feedstock (i.e. WFO). Besides, Gautam et al. [32] investigated the performance and emission characteristics of methyl and ethyl ester type biodiesels originated from jatropha oil and their blends with petrodiesel in the ratios of 5,10,20 and $30 \mathrm{vol} . \%$ in a diesel engine. Pure ethyl ester had a $1 \%$ lower density, $5.3 \%$ higher viscosity and $0.8 \%$ higher calorific value compared to that of pure methyl ester. In this study, the optimum blend ratio was found as $20 \%$ for diesel/methyl ester and diesel/ethyl ester blends. BSFC values of B20 (i.e. blend containing $20 \mathrm{vol} . \%$ biodiesel) of methyl ester and ethyl ester were respectively $9.8 \%$ and $8.6 \%$ lower than that of petrodiesel. BTE values of B20 of methyl ester and ethyl ester were $11 \%$ and $9.3 \%$ higher than that of diesel fuel, respectively. Consequently, the performance characteristics of ethyl and methyl esters were found to be close to each other. Besides, $\mathrm{NO}_{\mathrm{x}}, \mathrm{CO}, \mathrm{HC}$ and PM emissions were very similar for both ethyl and methyl esters. 


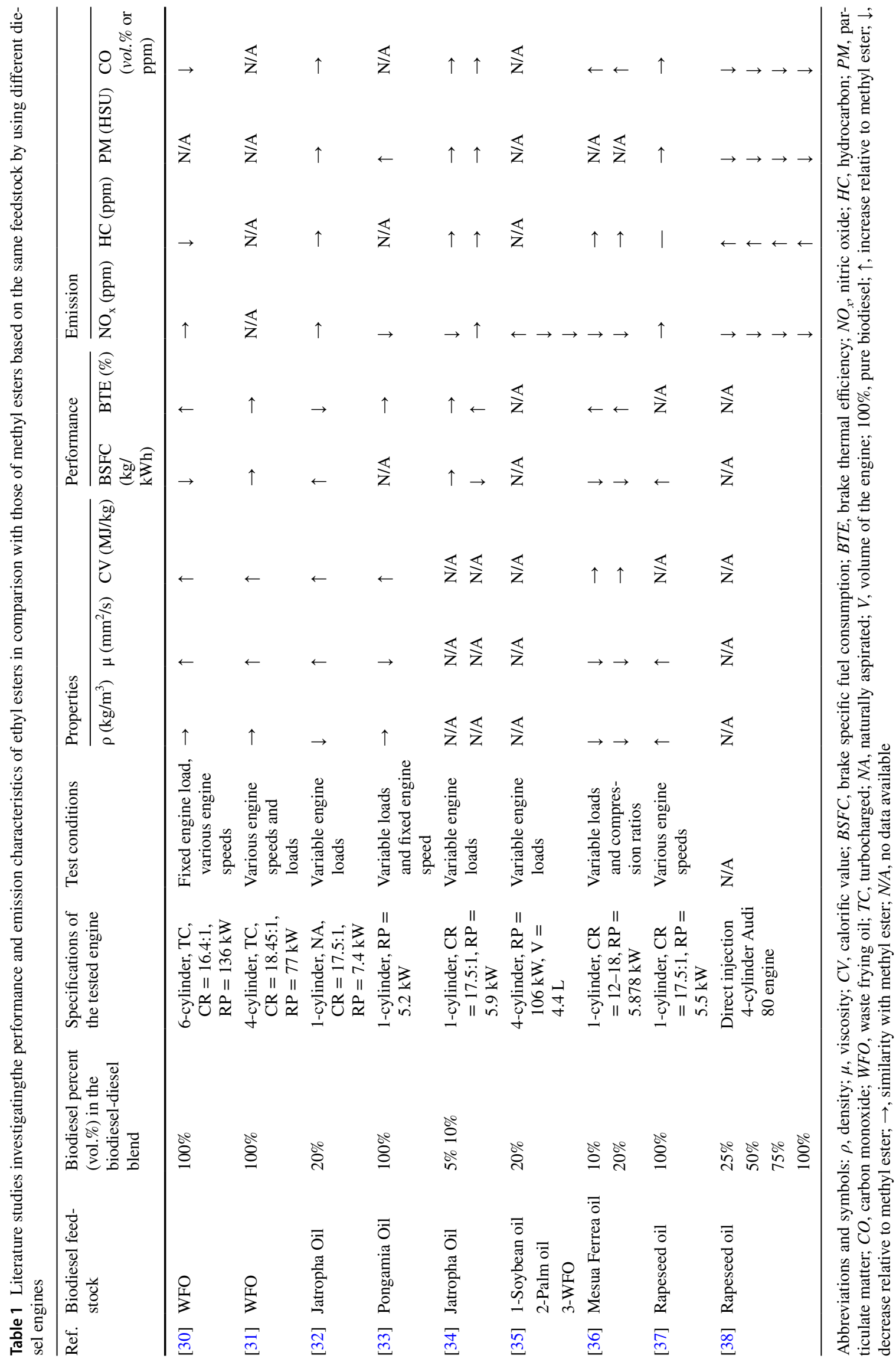


In compression ignition engines, fuel is directly injected via an injector into a chamber where the combustion of the fuel takes place. Hence, fuel atomization has a critical role in performance output and pollutant emissions. Fuel properties have a direct influence on spray characteristics. Biodiesel fuels generally have larger density, viscosity and surface tension values than petroleum-based diesel; this leads to higher spray penetration lengths, narrower spray cone angle values and larger droplet sizes [39-43]. Moreover, operating conditions strongly affect the spray characteristics, like fuel properties. Many research findings showed that spray cone angle widens, and spray penetration length reduces as the ambient pressure increases $[40,44]$. Injection pressure is also an important operational parameter. Numerous research studies $[43,45,46]$ showed that a rise in injection pressure increases the spray penetration length and spray cone angle, while some studies [44, 47, 48] reported that spray cone angle is insensitive to injection pressure. Besides, ambient temperature, nozzle diameter and combustion chamber design are other parameters affecting the spray characteristics $[49,50]$.

Since biodiesels are different compared to petroleum-based diesel fuels in density, viscosity and surface tension [51, 52], they can be further investigated in terms of their spray behaviour. Hence, it is important to perform research on the macroscopic and microscopic spray characteristics of alternative diesel fuels to figure out the effects of those fuels on the spraying process. Numerous studies concerning spray investigation of biodiesel fuels can be found in the literature [39-41, 50, 53]. However, all available literature studies have focused on spray patterns of methyl esters, which were produced via the utilization of fossil-based methanol in the transesterification process. Despite the importance of research focusing on spray characteristics, investigation on spray characteristics of ethyl ester type biodiesel fuels, to our best knowledge, is not yet available in the literature. Hence, this study intends to fill this important gap in the literature by investigating the spray characteristics, i.e. spray penetration length, spray cone angle and Sauter mean diameter of ethyl ester type biodiesel fuels derived from corn and sunflower oils in comparison to those of methyl esters based on the same feedstocks, and also of petrodiesel.

\section{Experimental}

\subsection{Biodiesel production}

Transesterification is a process that replaces the organic group of an ester with the organic group of alcohol, as shown in Fig. 1. For the production of biodiesel, $1 \mathrm{~mol}$ of triacylglycerol stoichiometrically reacts with $3 \mathrm{~mol}$ of alcohol in the presence of catalysts such as $\mathrm{NaOH}, \mathrm{KOH}$, etc., whereas, excess amount of alcohol is generally used to increase the biodiesel yield [54]. Biodiesel fuels tested in this study were produced from corn and sunflower oils (Kucukbay Oil and Detergent Inc. Trademark: Orkide). Against $1 \mathrm{~mol}$ of oil, 6 mol of methanol (to produce methyl ester) [55] and 24 mol of ethanol (to produce ethyl ester) [22] were used. Produced samples were referred to as CORME (corn oil methyl ester), SUNME (sunflower oil methyl ester), COREE (corn oil ethyl ester) and SUNEE (sunflower oil ethyl ester). All samples were produced at the Renewable Energy and Hydrogen Research Laboratory of İzmir Institute of Technology.

In this work, $\mathrm{KOH}$ was used as the catalyst. For the production of methyl and ethyl esters, catalyst-to-lipid ratios of $1 \mathrm{wt} . \%$ and $0.1 \mathrm{wt} . \%$ were respectively used. Apart from the alcohol and catalyst ratios used, the method, which is explained below, used for the production of both methyl and ethyl esters, was not changed. Reaction conditions are given in Table 2.

Transesterification procedures were started by preparing a catalyst-alcohol solution at room temperature. This solution was stirred at $1100 \mathrm{rpm}$ while it was being heated up to 50 ${ }^{\circ} \mathrm{C}$ (WiseStir MSH-20D, temperature uncertainty $\pm 0.3{ }^{\circ} \mathrm{C}$ ). When the temperature of the solution reached $50{ }^{\circ} \mathrm{C}$, it was stirred for an additional $10 \mathrm{~min}$ at the same stirring rate. In

Table 2 Reaction conditions for the transesterification process

\begin{tabular}{lll}
\hline Parameter & Methyl ester & Ethyl ester \\
\hline Type of alcohol & Methanol & Ethanol \\
Alcohol/lipid ratio & $6: 1$ & $24: 1$ \\
Catalyst & $\mathrm{KOH}$ & $\mathrm{KOH}$ \\
Catalyst/lipid ratio & $1 \mathrm{wt} \%$ & $0.1 \mathrm{wt} . \%$ \\
Reaction temperature $\left[{ }^{\circ} \mathrm{C}\right]$ & 50 & 50 \\
Reaction duration $[\mathrm{h}]$ & 4 & 4 \\
\hline
\end{tabular}

Fig. 1 Biodiesel production through transesterification process

\begin{tabular}{|c|c|c|c|c|c|c|}
\hline Triacylglycerol & & Alcohol & & Biodiesel & & Glycerol \\
\hline $\mathrm{CH}_{2}-\mathrm{COO}-\mathrm{R}_{1}$ & & & & $\mathrm{R}_{1}-\mathrm{COO}-\mathrm{R}^{\prime}$ & & $\mathrm{CH}_{2}-\mathrm{OH}$ \\
\hline $\mathrm{CH}-\mathrm{COO}-\mathrm{R}_{2}$ & + & 3 R'OH & Catalyst & $\mathbf{R}_{2}-\mathrm{COO}-\mathrm{R}^{\prime}$ & + & CH-OH \\
\hline $\mathrm{CH}_{2}-\mathrm{COO}-\mathrm{R}_{3}$ & & & & $\mathbf{R}_{3}-\mathrm{COO}-\mathrm{R}^{\prime}$ & & $\mathrm{CH}_{2}-\mathrm{OH}$ \\
\hline
\end{tabular}


the meantime, vegetable oil of which the biodiesel would be produced was heated to $50{ }^{\circ} \mathrm{C}$. Transesterification reaction was begun by adding vegetable oil into the alcohol-catalyst solution. The alcohol-vegetable oil mixture was stirred at $1100 \mathrm{rpm}$ for $4 \mathrm{~h}$. After $4 \mathrm{~h}$, the reaction was completed, and the mixture was left for glycerol precipitation. Glycerol precipitated in 4 $h$ and was accordingly separated from the biodiesel. Next, the washing process was applied to remove the impurities from the biodiesel. Washing of biodiesel was performed with $5 \mathrm{vol} . \%$ acetic acid solution in water with a determined $\mathrm{pH}$ which was 2.48. The acetic acid solution was added to the biodiesel in a ratio of $1 / 3 \mathrm{vol} / \mathrm{vol}$. Then, the acetic acid-biodiesel mixture was stirred for $1 \mathrm{~h}$ at a stirring speed of $500 \mathrm{rpm}$. After 1 $\mathrm{h}$, the acetic acid solution was separated from biodiesel. The washing step was repeated until the $\mathrm{pH}$ value of the acetic acid solution, which was removed from the biodiesel-acetic acid mixture, becomes the same as the $\mathrm{pH}$ value of the neat acetic acid solution. In the following step, biodiesel was subjected to a vacuum evaporation process for $24 \mathrm{~h}$ at a temperature of $75^{\circ} \mathrm{C}$. In this way, the remaining water molecules could be removed from the biodiesel. After vacuum evaporation, biodiesel was ready for use.

\subsection{Materials and fuel properties}

In this work, Shell V-Power Diesel having a product code of 002D2609 (Shell \& Turcas Petrol) was used as the reference fuel. More information is available in the diesel fuel data sheet [56].

The density values of diesel and biodiesel fuels were measured with a calibrated pycnometer at a temperature of $15{ }^{\circ} \mathrm{C}$. The pycnometer had a volume of $25.066 \mathrm{ml}$ with a sensitivity of $0.001 \mathrm{ml}$. AEK-Tech WT-1 thermometer (accuracy $\pm 1{ }^{\circ} \mathrm{C}$, sensitivity $0.1^{\circ} \mathrm{C}$ ) was utilized to measure the temperature of the fuels during density measurements.

A AR 2000ex rheometer of TA Instruments was utilized to measure the viscosity of the fuels. Measurements were performed in controlled rate mode with an angular velocity of $10.5 \mathrm{rad} / \mathrm{s}$ as the input for rotating plates of the rheometer. All measurements were made for fuel temperatures of $40{ }^{\circ} \mathrm{C}$. In addition, 60 data were collected with a sampling rate of 5 for each viscosity measurement of each fuel at the specified conditions in order to ensure the accuracy of the measurements. Viscosity values of the fuels reached steady-state values during obtaining 60 data. After reaching steady state, the values did not change with respect to time anymore. The viscosity values stated in Table 3 are the steady-state values.

In order to predict the surface tension effects of the fuels, contact angle values of all fuels were measured with glass at room temperature. Theta Optical Tensiometer (Attension), which had an accuracy of $\pm 0.1^{\circ}$, was used to measure the contact angle values.

The physical properties of the fuels are presented in Table 3. Besides, viscosity and density values of ethyl ester type biodiesel fuels were compared with the tested ethyl ester type biodiesel fuels based on different feedstocks in literature studies. This comparison is presented in Fig. 2, where the density and viscosity values of ethyl esters produced from various sources differ $1.6 \%$ and $22.1 \%$ on average, respectively.

As can be seen in Table 3, the physical properties of biodiesel fuels differ from those of the reference petrodiesel. Density, viscosity and contact angle values of both methyl and ethyl esters were higher than those of diesel. CORME and SUNME respectively had higher densities by $6.5 \%$ and 6.2\%; higher viscosities by 1.9 and 1.7 times and larger contact angle values by $39.1 \%$ and $38.3 \%$ than fossil diesel. Density values of COREE and SUNEE were respectively $5.3 \%$ and $4.4 \%$ higher than the density of diesel. The viscosity of COREE and SUNEE was 2.2 and 1.9 times higher than that of conventional diesel while the contact angle values of COREE and SUNEE were $35.8 \%$ and $34.5 \%$ larger.

The physical properties of ethyl esters can be compared with that of methyl esters' produced from the same

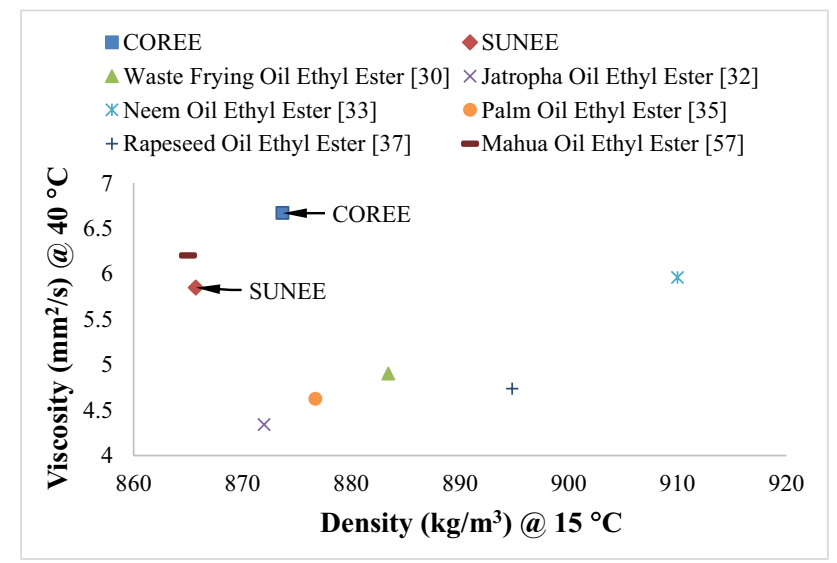

Fig. 2 Comparison of physical properties of ethyl esters with literature studies [30, 32, 33, 35, 37, 57]
Table 3 Physical properties of the tested fuels

\begin{tabular}{llllll}
\hline Test fuel & Diesel & CORME & SUNME & COREE & SUNEE \\
\hline Viscosity $\left(\mathrm{mm}^{2} / \mathrm{s}\right) @ 40^{\circ} \mathrm{C}$ & 3.07 & 5.83 & 5.17 & 6.67 & 5.85 \\
Density $\left(\mathrm{kg} / \mathrm{m}^{3}\right) @ 15^{\circ} \mathrm{C}$ & 829.55 & 883.26 & 880.83 & 873.69 & 865.71 \\
Contact angle $\left({ }^{\circ}\right)$ with glass @ $25^{\circ} \mathrm{C}$ & 14.71 & 20.46 & 20.34 & 19.98 & 19.78 \\
\hline
\end{tabular}


feedstock. Although physical properties of biodiesels vary limitedly among themselves, ethyl esters had lower density and contact angle values than that methyl esters; on the contrary, their viscosity values were higher than those of methyl esters. COREE had $1.1 \%$ lower density, 1.1 times bigger viscosity and $2.4 \%$ decreased contact angle values than CORME. The density of SUNEE was $1.7 \%$ lower than the density of SUNME. The viscosity value of SUNEE was 1.1 times bigger than that of SUNME. SUNEE had a $2.8 \%$ reduced contact angle value than SUNME.

\subsection{Experimental setup}

Fuel spray experiments were conducted in a bench-scale spray test setup (Fig. 3) consisting of a constant volume chamber (CVC) and with fuel injection, gas filling, optical and control systems. The setup allows reactive and nonreactive spray measurement. In this work, the target was observing the influence of the physical properties of ethyl ester on the spray characteristics, rather than its methanol counterpart (i.e. methyl ester). Hence, only a non-reactive spray study was carried out. A non-reactive environment can be achieved by adding nitrogen gas into the chamber.

To inject the test fuels into the chamber a fuel injection system was employed in the test setup. The injector, common rail, fuel pump, fuel filter and fuel tank are the components of the fuel injection system. A Siemens brand diesel injector with originally 7 holes of which 6 holes were closed by laser welding was used. In this way, it was possible to focus on the formation of only one spray.

The setup allows the identification of the liquid phase of fuel sprays via an optical system based on the shadowgraph method (Fig. 3). The chamber was established with quartz windows allowing optical accessibility. The spray visualization system consists of 7 components such as optical table, high-speed camera, a convex lens, parabolic mirror, off-axis mirror mount, light source and diaphragm. Table 4 gives information about the equipment employed in the optical setup. Furthermore, the high-speed camera was utilized to record an injection event at 20,000 fps, shutter speed of $1 / 62,000$ with a resolution of $512 \times 512$ pixels during the experiments.

A control system is responsible for controlling the equipment, receiving and transmitting the data. This system consists of a computer, National Instruments (NI) USB 6343 and USB 6353 data acquisition (DAQ) cards. A control programme was prepared in LabVIEW software to process the data, and to give necessary commands. Mainly, the control system can amplify the signal going to the motor of the fuel pump via motor drivers, adjust the fuel injection pressure, start and stop injection event and start and stop image recording. Besides, the control system can measure and control the chamber pressure and temperature with the equipment listed in Table 5.

Total uncertainty (u) of the experiments can be found by taking the square root of the sum of squares of uncertainty
Fig. 3 Schematic of the experimental setup

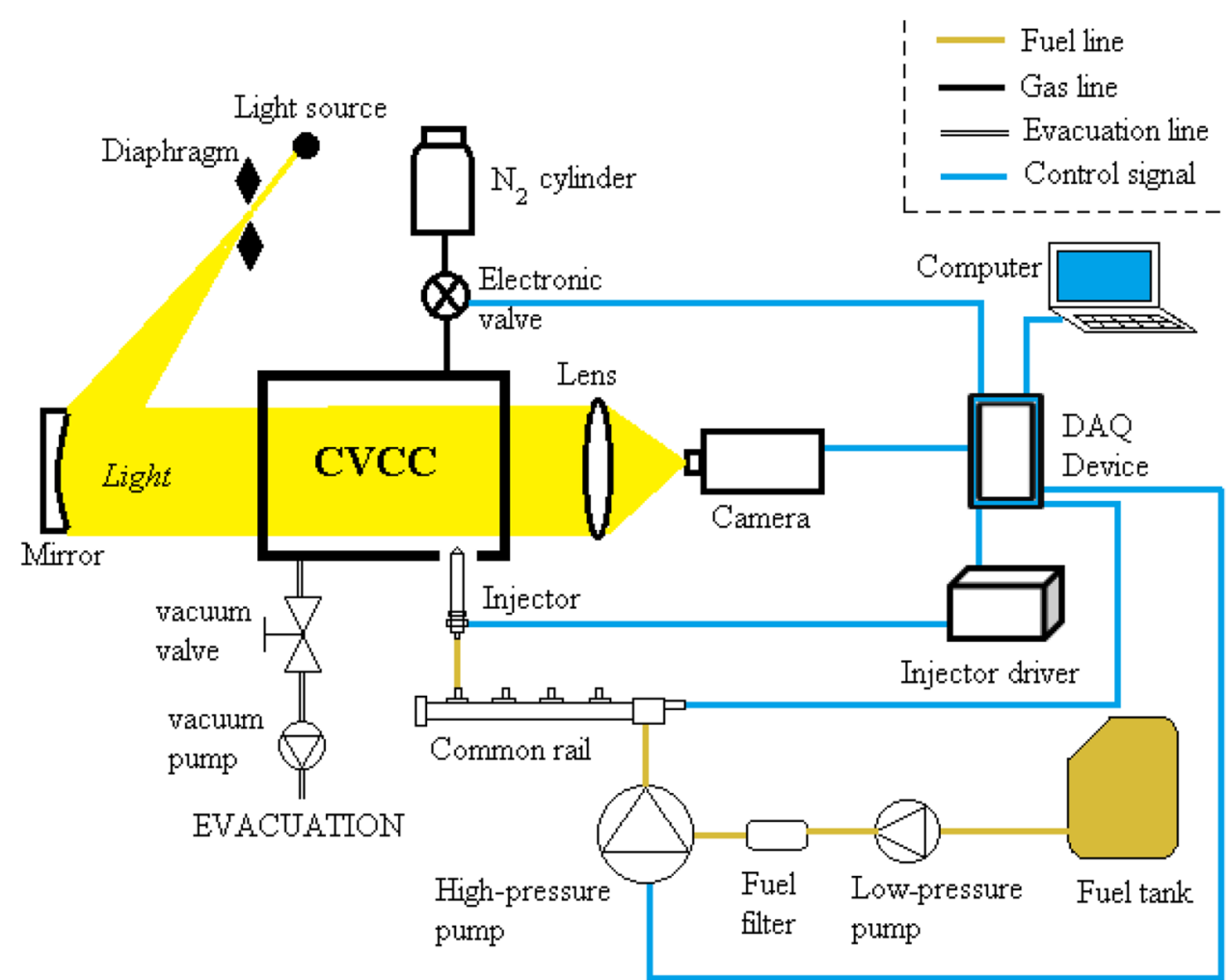


Table 4 The list of equipment in the optical system

\begin{tabular}{ll}
\hline Component & Model and/or property \\
\hline Optical table & $600 \times 1200 \mathrm{~mm}$ metric optical table \\
Light source & Edmund Optics MI-150 fibre light source, $150 \mathrm{~W}$ quartz halogen \\
Diaphragm & Diameter of $30.8 \mathrm{~mm}$, aperture: $0.8-12 \mathrm{~mm}$ \\
Mirror mount & Parabolic mirror mount with a diameter of $101.6 \mathrm{~mm}$ \\
Off-axis parabolic mirror & Edmund Optics $101.6 \times 152.4 \mathrm{~mm}$ EFL $90^{\circ}$ protected alumin- \\
& ium $100 \AA$ Aff-axis parabolic mirror \\
Convex lens & Diameter: $125 \mathrm{~mm}$, focal length: $250 \mathrm{~mm}$ \\
High-speed camera & Photron SA 1.1 with a Sigma lens (Sigma $24-70 \mathrm{~mm} \mathrm{f/1:2.8)}$ \\
\hline
\end{tabular}

\begin{tabular}{llll}
\hline Equipment & Parameter & Range (Units) & Accuracy \\
\hline MAX6675 K-type thermocouple & Temperature & $-20-80\left({ }^{\circ} \mathrm{C}\right)$ & $0.25 \%$ \\
Emko ESM-4420 temperature control device & Temperature & $0-50\left({ }^{\circ} \mathrm{C}\right)$ & $0.25 \%$ \\
Kistler 4075A50V200S pressure sensor & Pressure & $0-50(\mathrm{bar})$ & $0.1 \%$ \\
$\begin{array}{l}\text { Kistler Piezoresistive amplifier type 4624A (for } \\
\text { pressure measurement) }\end{array}$ & Voltage output & $0-10(\mathrm{~V})$ & $0.05 \%$ \\
& Error of the electronics & & $0.75 \%$ \\
\hline
\end{tabular}

Table 5 Measurement devices employed in the spray test rig values for measurement devices [58], which are listed in Table 5. Total uncertainty for this study was calculated as $\pm 0.84 \%$.

\subsection{Test conditions}

Experiments were conducted under variable chamber pressures of $0,5,10$ and $15 \mathrm{bar}$, and variable injection pressures of 600 and 800 bar, while the chamber was kept constant at room temperature. The injection pressures were utilized since the fuel pump is not stable at higher injection pressures. An installed experimental setup can achieve these pressure values. In addition, fuel impingement to the chamber wall could occur at higher injection pressures, e.g. 1200-1800 bar. At these pressures, it might be difficult to distinguish the spray characteristics of different fuels. Moreover, the values for the chamber pressure were selected to observe the mixing effect of air because air viscosity varies with the pressure. Besides, injection duration was kept at 1 ms. Table 6 shows the test conditions, which were selected based on existing literature [39, 43, 44, 48, 52, 53].

Tests were repeated five times for all test conditions to ensure the accuracy of the study. Mean values of the experiments were calculated, and it was observed that the deviation of the experimental results from the mean values, which was named repeatability, did not exceed $5 \%$. The results were presented as the mean values of the tests corresponding to each experimental condition. Besides, uncertainty values for the experiments were already given as $\pm 0.84 \%$. Repeatability bars are shown on the graphs in the results section. Because the uncertainty value was smaller than the
Table 6 Experimental conditions

\begin{tabular}{ll}
\hline Condition & Property \\
\hline Injector type & Piezoelectric common rail injector \\
Number of the nozzle holes & 1 \\
Injection angle into the chamber & $45^{\circ}$ (clockwise direction) \\
$\quad$ w.r.t. horizontal axis & \\
Chamber temperature & $25^{\circ} \mathrm{C}$ \\
Chamber pressure (absolute) & $0,5,10,15$ bar \\
Injection pressure & 600,800 bar \\
Injection duration & $1 \mathrm{~ms}$ \\
Repetition of the experiments & 5 times for each test condition \\
\hline
\end{tabular}

repeatability value, uncertainty bars were not included in the graphs.

\subsection{Image processing}

SPL is the length between the furthest point of the spray on its axis and the nozzle of the injector. SCA can be defined as the angle between the tip of the injector and the two outermost points on the spray boundary. SCA can be measured from the points corresponding to $50 \%$ of the spray length according to the literature [44, 59, 60]. The spray images were recorded by a high-speed camera during the experiments. These images were then processed in order to measure spray characteristics, accurately. ImageJ [61] and MATLAB were utilized for image processing. Procedures for image processing are presented in Fig. 4. First of all, spray images were subjected to background subtraction so that only the spray shape remained. The recording of the 
Fig. 4 Image processing procedures

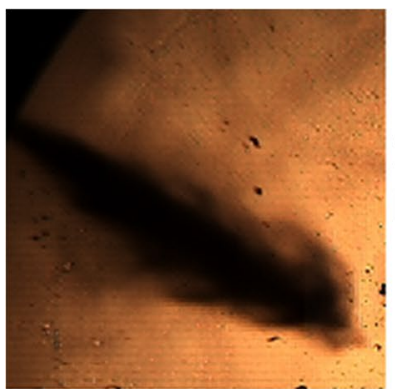

Original spray image

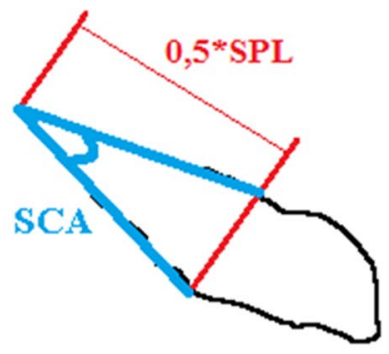

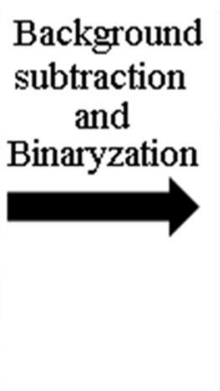

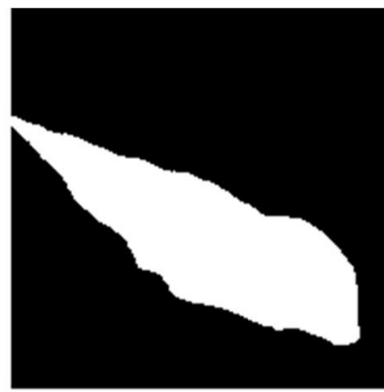

Edge detection

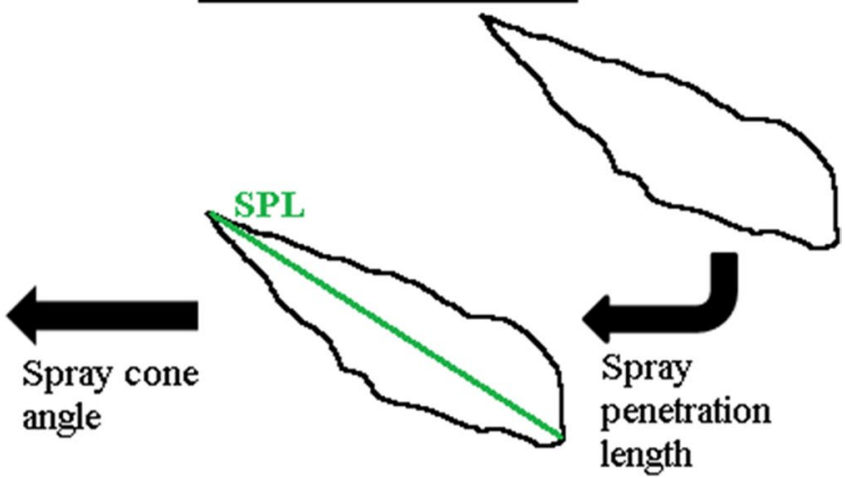

spray images took place simultaneously with the initiation of the injection process. The image recording started 4 frames before the spray operation so the background image of the spray process was obtained. This background was then subtracted from each spray image, and images containing only fuel spray were obtained. Images from step one were converted to binary images by applying thresholding. The threshold value was calculated using Otsu's method [62], and this value corresponded to 0.4 . In the third step, boundaries of the spray images were detected and spray penetration lengths were measured. After obtaining the SPL values, lengths corresponding to $50 \%$ of the spray penetration lengths $(0.5 \cdot S P L$ values $)$ were calculated, and spray cone angles were measured by considering the $0.5 \cdot S P L$ values.

\section{Results and discussions}

All fuels including methyl esters, ethyl esters and fossil diesel fuel showed similar macroscopic spray shapes with minor differences under the variable chamber and injection pressures. Increasing the ambient pressure reduced the spray penetration lengths (Figs. 5 and 6), on the other hand, widened the spray cone angles for all fuels (Figs. 7 and 8). Increasing the chamber pressure raised the gas density in the chamber. This led to more resistance to spray at the tip and decreased spray propagation in the spray axis significantly. Continuous mass flow from the injector during the injection process caused the spray to spread in the radial direction because of the inhibited penetration in the axial direction, which resulted in an enlarged spray angle [44]. This result is consistent with the study by Lee et al. [40]. They explained that increased ambient pressure led to enlarged spray angles and a longer time to reach a specified spray penetration length. Besides, increasing the injection pressure increased the penetration lengths (Fig. 6) while keeping the spray cone angles almost unchanged (Fig. 8). Increasing the injection pressure raised the kinetic energy of the spray, which enhanced the spray process in the axial direction as well as the radial direction. But, the growth in the axial direction was remarkably quicker than it was along the radial direction [44]. Therefore, spray tip penetration increased while rising the injection pressure on the contrary no change occurred in the spray cone angle under the given experimental conditions. Wang et al. [47] also observed an increase in the spray penetration length while spray cone angle values remained almost constant with raise in fuel injection pressure.

Besides, the chamber pressure was found to be more effective on spray characteristics than fuel injection pressure. For example, spray penetration lengths of diesel at zero chamber pressure at $0.4 \mathrm{~ms}$ of the injection were approximately $91.2 \mathrm{~mm}$ and $102.4 \mathrm{~mm}$ for injection pressures of 600 and 800 bar, respectively. The difference was approximately $11.2 \mathrm{~mm}$. Spray cone angle values under the same conditions were respectively found to be as $8.2^{\circ}$ and $8.4^{\circ}$ for injection pressures of 600 and 800 bar. From another point of view, penetration lengths of diesel fuel at an injection pressure of 600 bar at the same instant of the injection were approximately $91.2 \mathrm{~mm}$ and $46.5 \mathrm{~mm}$ for 
Fig. 5 (a, b) Spray penetration length (SPL) values for ethyl esters under variable injection pressures in comparison to diesel and methyl esters, where $\mathrm{Pc}=$ chamber pressure
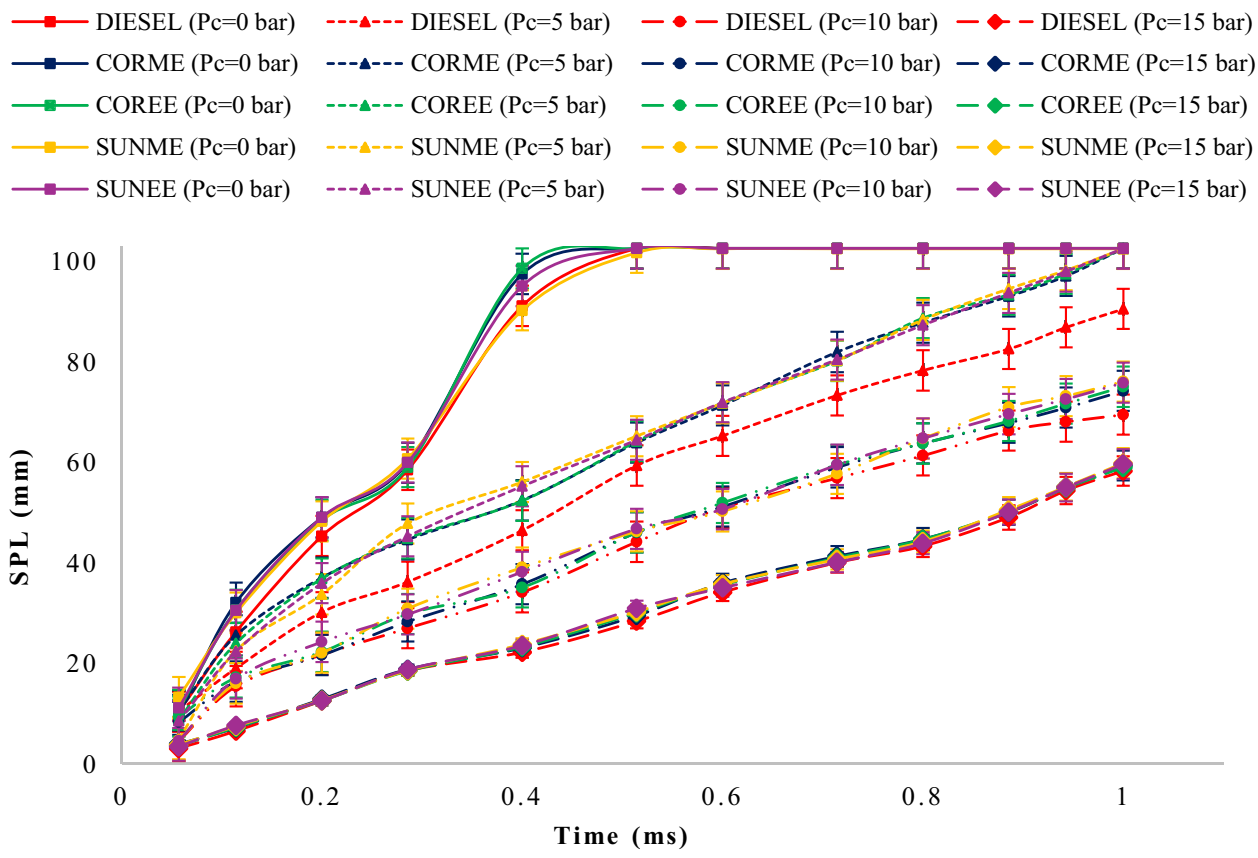

(a) Injection pressure of $600 \mathrm{bar}$

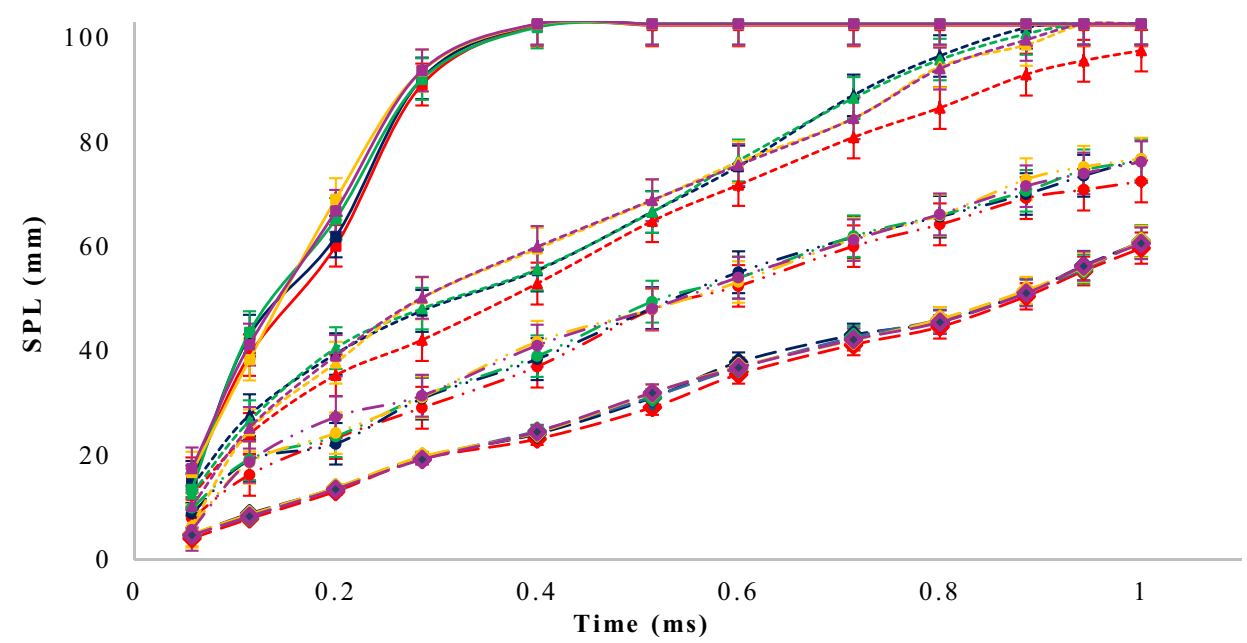

(b) Injection pressure of 800 bar

In addition, the difference between spray penetration lengths at injection pressures of $600 \mathrm{bar}$ and $800 \mathrm{bar}$ decreased as the pressure inside the chamber increased as shown in Fig. 9. For instance, this difference was found as $7.8 \mathrm{~mm}$ for COREE at $0.8 \mathrm{~ms}$ of the injection when chamber pressure was 5 bar. However, this difference decreased to 3.3 $\mathrm{mm}$ and $1.3 \mathrm{~mm}$ when the ambient pressure was respectively increased to 10 and 15 bar. Namely, increasing the chamber pressure reduced the effects of increasing the injection pressure.

On the one hand, higher injection pressures (even larger injection pressures than the pressures used in this study) may 
Fig. 6 Variations in spray penetration length (SPL) values for ethyl esters in comparison with reference diesel fuel and methyl esters at chamber pressures of a 0 bar, b 5 bar, c 10 bar and d 15 bar, where $\mathrm{Pi}=$ injection pressure
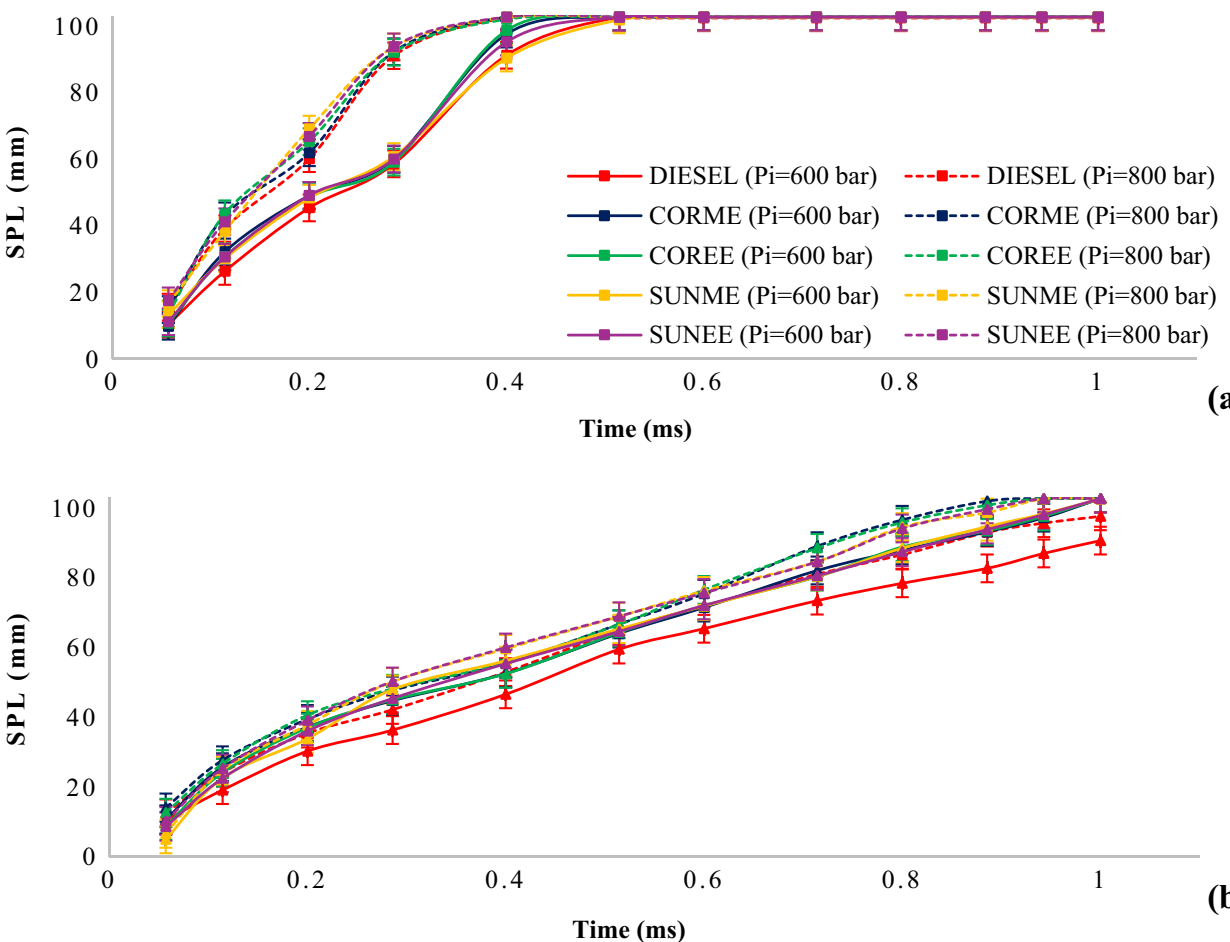

(b)

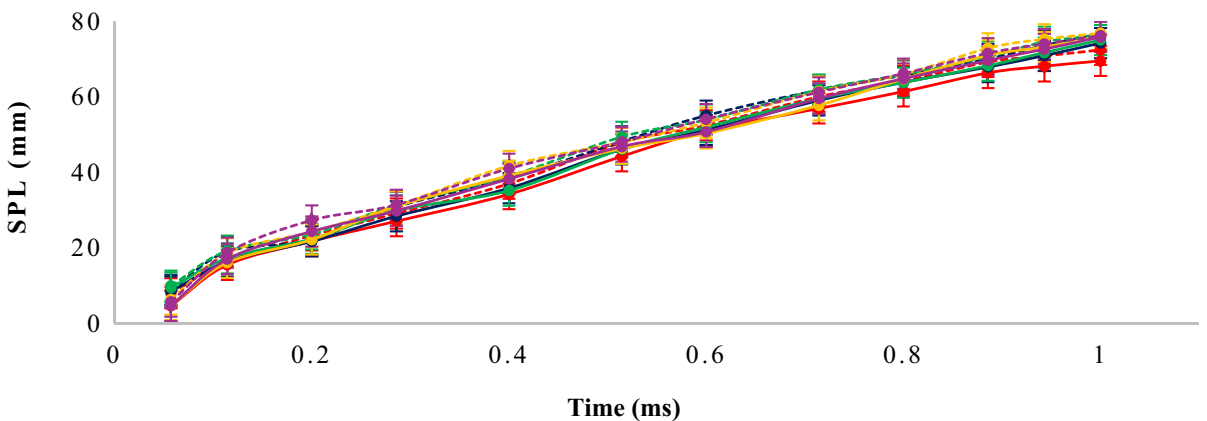

(c)

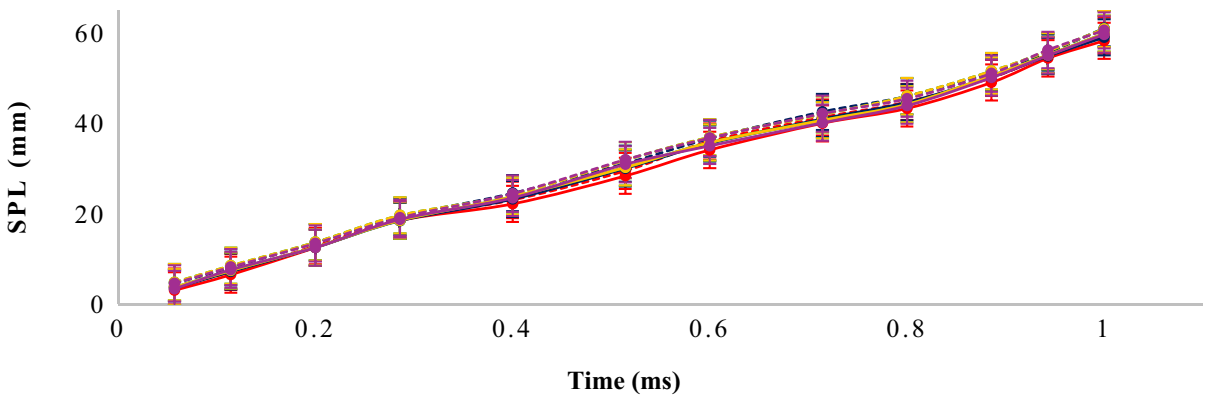

be beneficial due to the possible improvement in atomization as demonstrated in this study. The primary breakup of the fuel jet starts soon after leaving the injector nozzle and large droplets form near the nozzle. The main driving mechanisms for the primary breakup are cavitation and turbulence in case the injection pressure is high [64]. Then, existing droplets break up into smaller ones. This process is called secondary breakup and mainly occurred by the relative velocity between the fuel droplets and the air [65].
Increasing the injection pressures raises the fuel velocity resulting in a larger $\mathrm{Re}$ number, which is presented in the following equation:

$\operatorname{Re}=\frac{u D \rho_{l}}{\mu_{l}}$

where $\mu_{1}$ is the fuel viscosity, $\rho_{1}$ is fuel density, D is the nozzle diameter and $u$ is the jet velocity. It can be expected that 
Fig. 7 (a, b) Spray cone angle (SCA) values for ethyl esters under variable injection pressures in comparison to those of diesel and methyl esters

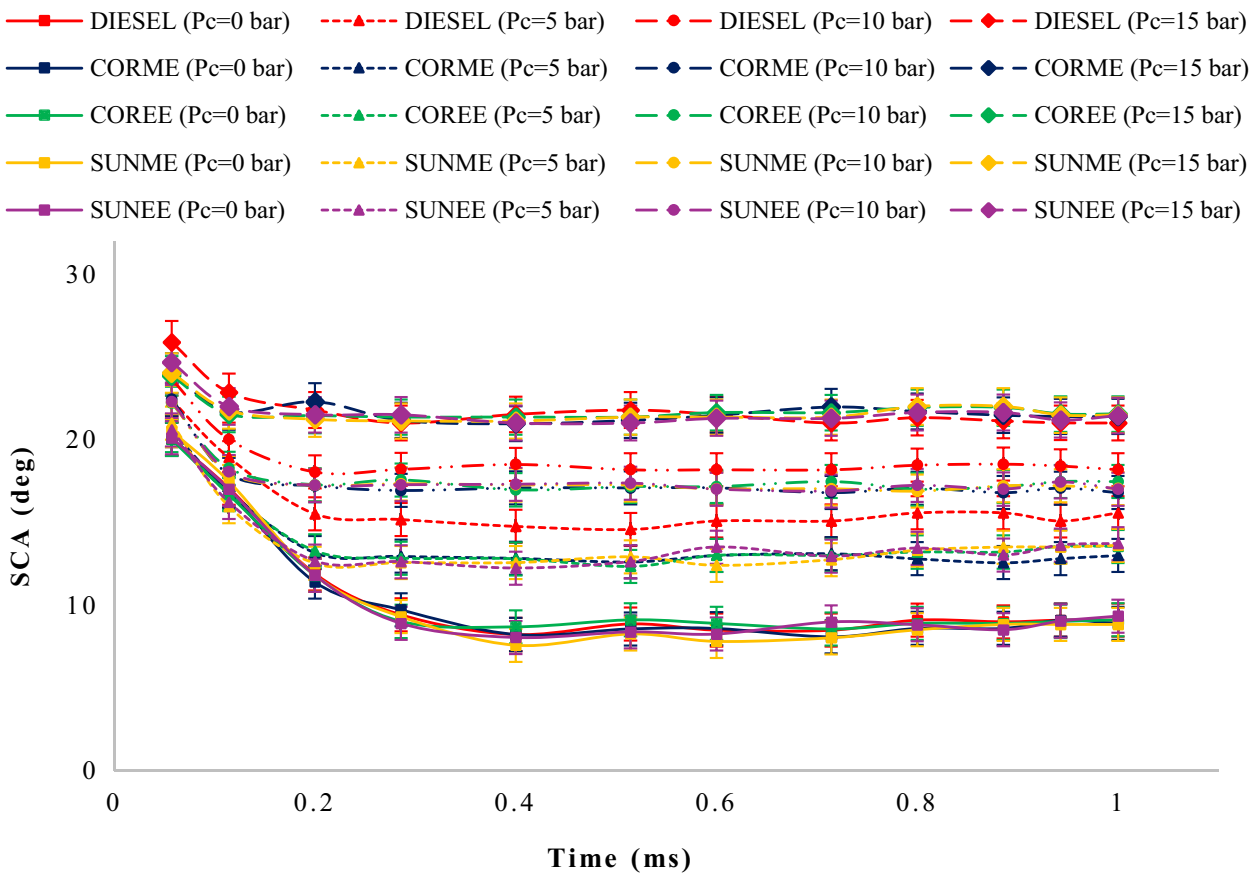

(a) Injection pressure of 600 bar

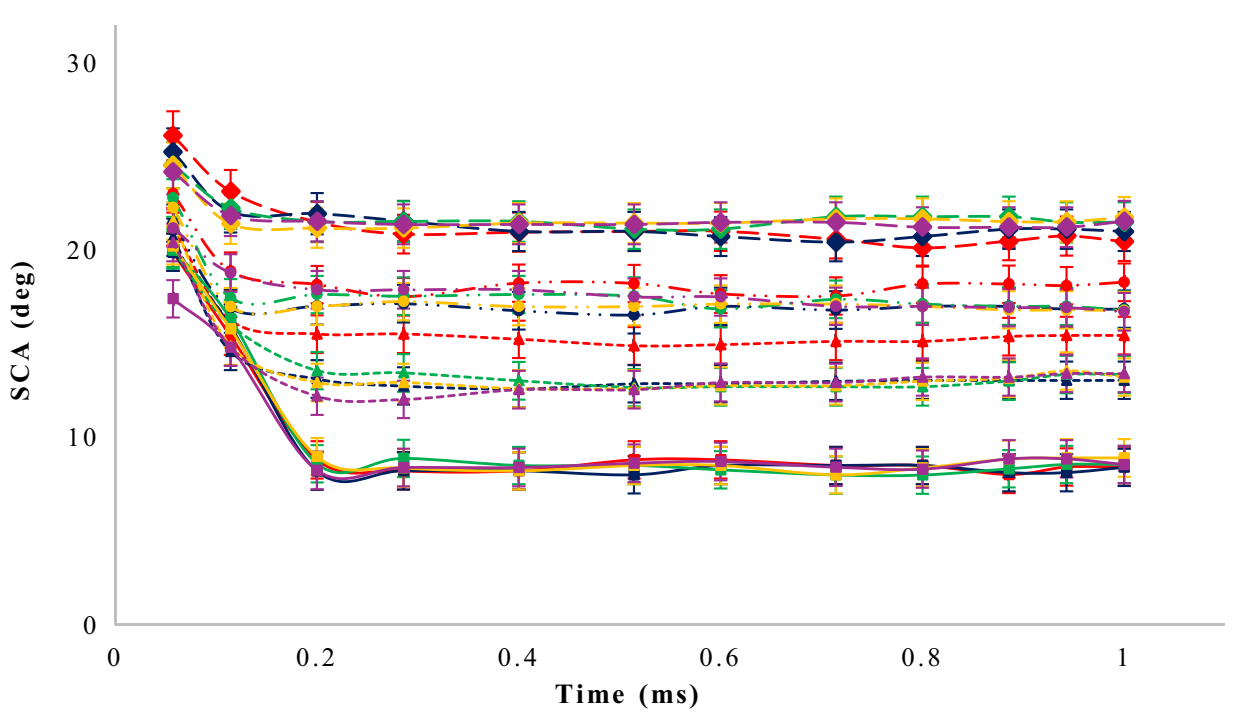

(b) Injection pressure of $800 \mathrm{bar}$ the fuel droplets should get more inertia against breakup leading to increased droplet diameter, based on raised $\mathrm{Re}$ number. However, when the injection pressure increases, the relative velocity between the fuel droplets and the almost stagnant air also increases. This air drag manifests itself as a fluctuating pressure and shear on the fuel droplet due to the high Re number. Therefore, an improvement in a secondary breakup can be expected, and the larger droplets disintegrate into smaller ones. Then, decreased droplet sizes can be achieved as a result of secondary breakup caused by high injection pressure [65]. Besides, Yadav and Gautam [66] explained that utilizing high injection pressures can reduce the rheological properties of fuels such as its surface tension. In case of variation in fuel velocity and fuel properties as a result of high injection pressures, Re number would change as well as Ohnesorge number $(\mathrm{Z}) . \mathrm{Z}$ is a dimensionless number to define the jet breakup regimes, which includes all relevant properties of fuel, as shown in Eq. (2) [65]: 
Fig. 8 Variations in spray cone angle (SCA) values for ethyl esters in comparison with reference diesel fuel and methyl esters at different chamber pressures of a 0 bar, b 5 bar, c 10 bar and $\mathbf{d} 15$ bar

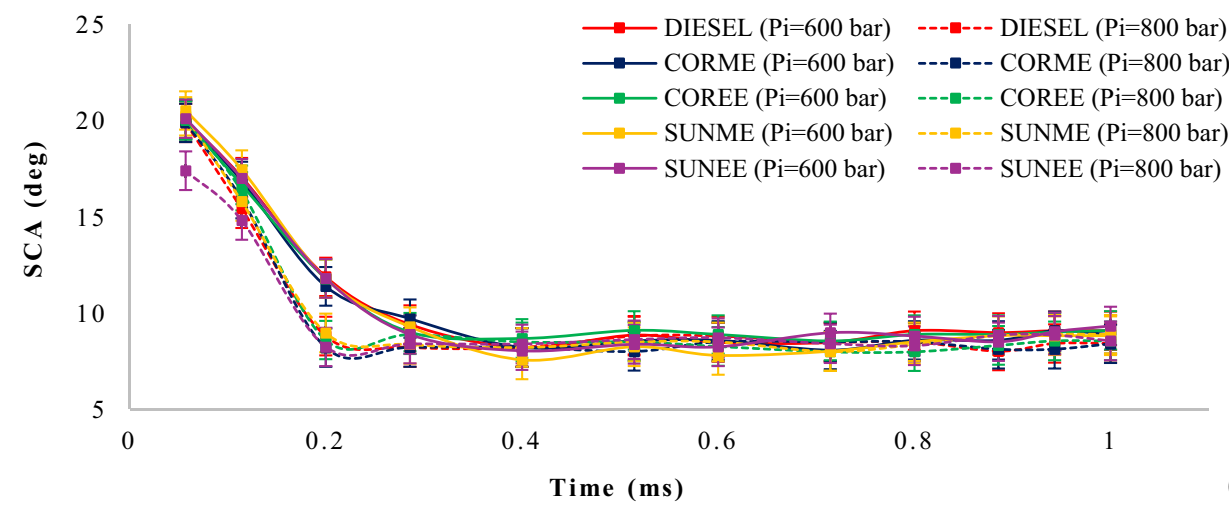

(a)

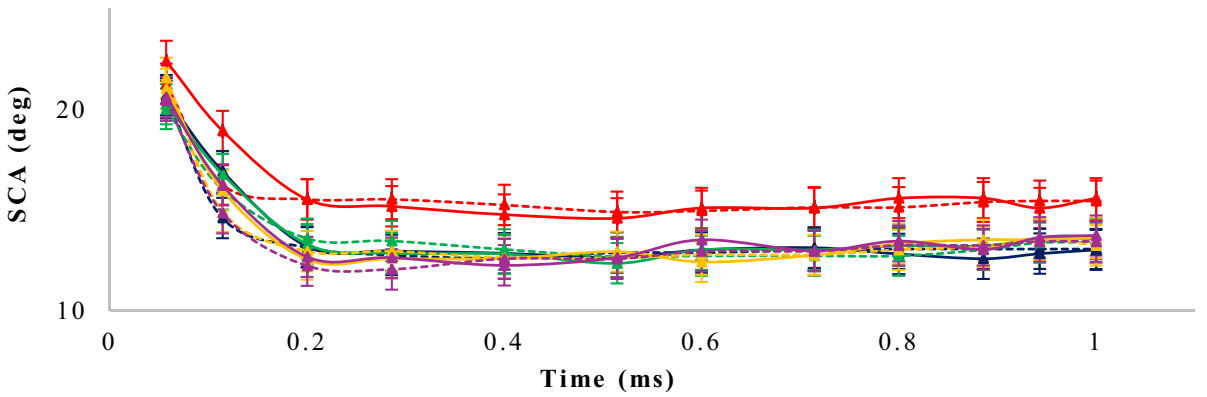

(b)

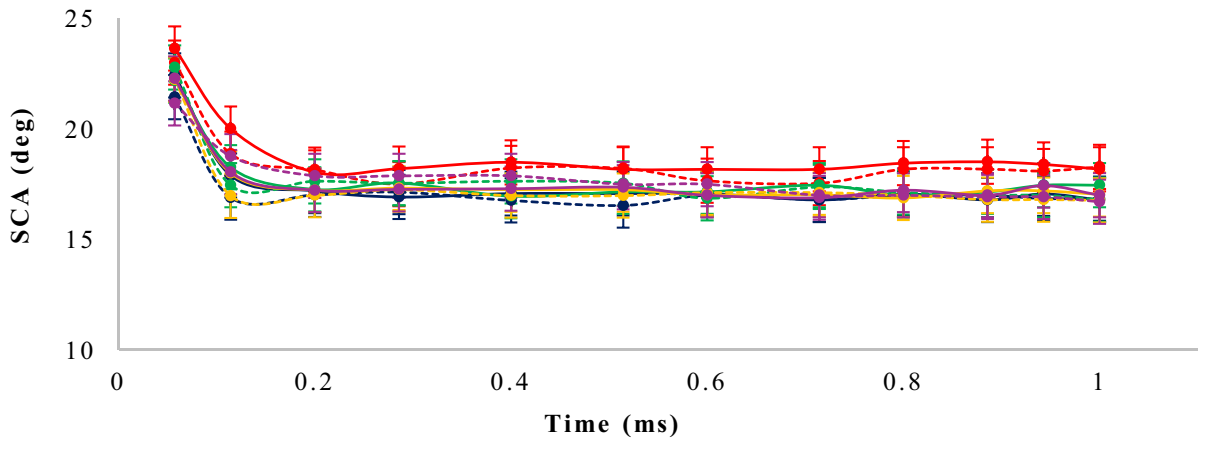

(c)

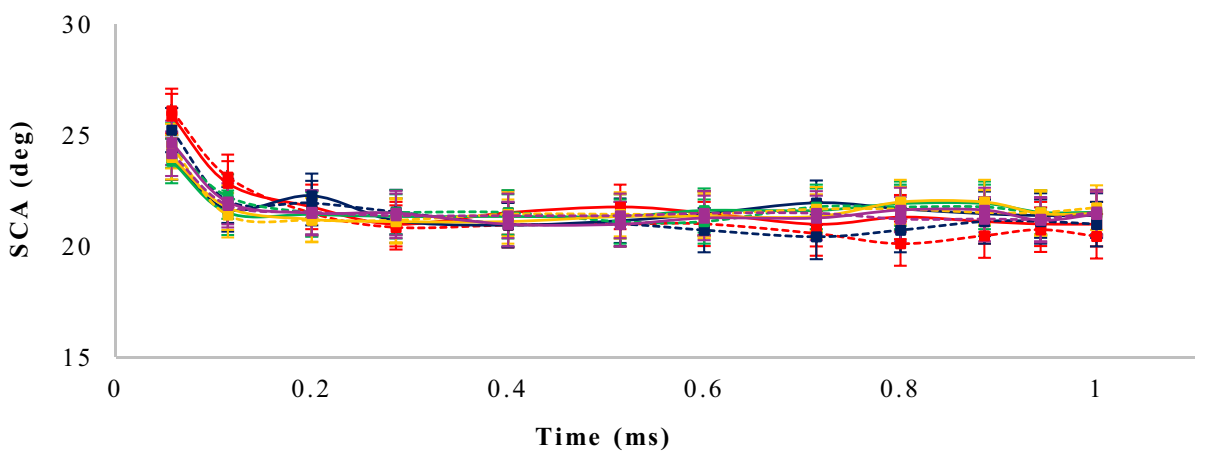

(d)
$Z=\frac{\mu_{l}}{\sqrt{\sigma \rho_{l} D}}$

where $\sigma$ is the surface tension of a fuel. Re number increases due to the increase in inertial effects more than viscous effects. $\mathrm{Z}$ number may also rise owing to possible slight changes in rheological properties. Thence, fuel atomization is enhanced. This is supported by the previous explanation regarding the second breakup as a consequence of an increase in injection pressure. On the other hand, this is an issue that needs attention. Very high injection pressures can have the possibility of wall impingement in diesel engines causing an increase in fuel consumption as well as $\mathrm{HC}$ and PM emissions [66, 67].

Furthermore, spray penetration curves could be divided into two phases which were the rapid development phase and steady development phase. Spray penetration length rapidly increased in the rapid development phase then passed to the steady development phase in which spray penetration steadily increased and reached the maximum value. Besides, 


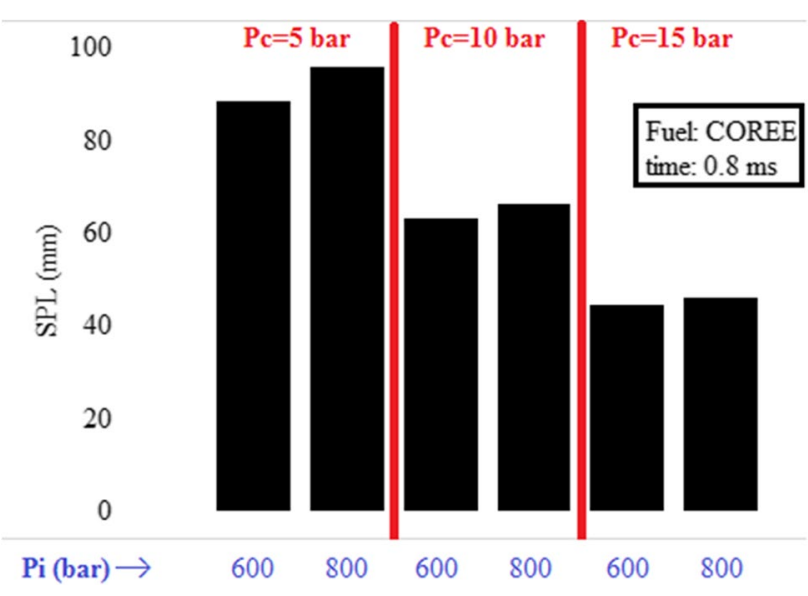

Fig. 9 Effects of chamber and injection pressures on SPL

differences between the biodiesels and fossil diesel occurred in the steady development phase while similar penetrations were observed in the rapid development phase. This is consistent with the literature $[68,69]$. Also, spray cone angle curves could be divided into two phases: the transient and the steady phases. Besides, these regions are related to the needle valve of the injector $[68,69]$. In the transient phase, the needle valve was partially open, and radial momentum was high. These caused the spray cone angle to increase abruptly. In the steady phase, the needle valve was fully open, and radial momentum decreased. Then, the spray cone angle reduced and became almost constant.

At zero chamber pressure, no significant distinctions between ethyl esters and reference diesel fuel were found under both injection pressures when the uncertainty and repeatability values are taken into account as it is seen in Figs. 6a and 8a. All fuels impinged to the wall of the chamber by penetrating fast during the first $0.5 \mathrm{~ms}$ of the injection process.

When the ambient pressure was increased to 5 bar, pronounced differences were observed between diesel and ethyl esters in terms of spray penetration length and spray cone angle (see Figs. 6b and 8b). Ethyl esters had larger spray penetration length and reduced spray cone angle values than reference diesel fuel. For instance, COREE could be compared with diesel under an injection pressure of 600 bar at $0.8 \mathrm{~ms}$ of the injection duration. Spray penetration lengths were respectively measured as 88.7 and $78.3 \mathrm{~mm}$ for COREE and diesel. Spray cone angle values were found to be $13.2^{\circ}$ and $25.6^{\circ}$ for COREE and diesel, respectively. In addition, spray wall impingement was observed for biodiesel fuels at the end of the injection process for both injection pressures of 600 and 800 bar. However, diesel fuel did not impinge to the chamber wall.

When the chamber pressure was further raised to 10 bar, any fuel did not impinge to the wall. Moreover, the difference between spray characteristics of ethyl esters and fossil diesel decreased while ethyl esters still had higher spray penetration lengths and narrower spray cone angle values as shown in Figs. $6 \mathrm{c}$ and $8 \mathrm{c}$. For example, SUNEE had a spray cone angle of $17.5^{\circ}$ and spray penetration length of $54.1 \mathrm{~mm}$ at $0.6 \mathrm{~ms}$ of the injection under an injection pressure of 800 bar. Under the same conditions, spray penetration length and spray cone angle values of diesel were respectively measured as $52.4 \mathrm{~mm}$ and $16.7^{\circ}$.

Hereby, it can be stated that fuel properties directly affect the spray characteristics. Ethyl esters had longer spray penetration lengths and narrower spray cone angle values under chamber pressures of 5 and 10 bar for injection pressures of 600 and 800 bar. These results can be explained with higher contact angle, density and viscosity values of ethyl esters than diesel. Having higher contact angle values shows that surface tension effects of ethyl esters are greater than fossil diesel leading to decreased disintegration of spray resulting in narrower spray angles and increased liquid lengths [39]. Also, viscosity is effective for spray characteristics. Because, higher viscosity reduces the fuel atomization leading to narrower spray angles and deeper spray penetration lengths [41]. In addition, higher density values can increase the momentum of fuel spray thus extends the penetration lengths [43].

At the chamber pressure of 15 bar, the difference between diesel and ethyl esters further reduced in terms of both spray penetration length and spray cone angle (Figs. $6 \mathrm{~d}$ and $8 \mathrm{~d}$ ). At this pressure level, the differences between ethyl esters and reference diesel were so small that can be neglected. For instance, the distinction between spray cone angle values of COREE and conventional diesel were measured as $0.4^{\circ}$ at the end of the injection duration under injection pressure of 800 bar. At the same conditions, the difference between diesel and COREE in terms of spray penetration length was found to be $1 \mathrm{~mm}$. When considering the uncertainty and repeatability, these differences have no point.

Moreover, it can be stated that the difference between ethyl esters and the petrodiesel decreased in terms of both spray characteristics as the chamber pressure increased. At zero chamber pressure, it was explained that diesel and ethyl esters had very similar spray characteristics because there was no air inside the chamber leading to neither turbulent mixing nor shear drag. This might explain the lack of distinction between diesel and ethyl esters. However, the situation was different when there was pressure inside the chamber, especially at 5 bar. Kinematic viscosity of air decreases as the density of the air inside the chamber increases. Reduced kinematic viscosity of air could improve the mixing of fuelair because the air becomes more prone to turbulence as its kinematic viscosity gets smaller. Hence, air turbulence around the fuel spray may lead to the disintegration of the fuel spray. Since the surface tension effects of fossil diesel fuel were lower than ethyl esters, the air mixed the diesel 
fuel more than ethyl esters leading to wider spray cone angles and reduced spray lengths when the ambient pressure was 5 bar. But, the kinematic viscosity of air became smaller when the ambient pressure was further raised. Thence, ethyl esters could be effectively mixed with air as similar as the reference diesel mixes with air due to the higher air turbulence at higher air densities. This may explain the reduction in differences of spray characteristics for ethyl esters and diesel as the ambient pressure increased and the similarity between diesel and ethyl esters at 15 bar ambient pressure.

When comparing the spray parameters of ethyl esters with methyl esters, a similarity was observed. For example, spray penetration lengths at $0.6 \mathrm{~ms}$ of the injection for CORME and COREE were respectively measured as $71.4 \mathrm{~mm}$ and $71.9 \mathrm{~mm}$ at an injection pressure of 600 bar under chamber pressure of 5 bar. As another example, penetration lengths of SUNME and SUNEE were respectively found as 71.7 $\mathrm{mm}$ and $71.8 \mathrm{~mm}$ under the same conditions. Besides, this likeness was observed for spray cone angle curves of both types of fuels. For instance, spray angles of CORME and COREE were respectively measured as $16.9^{\circ}$ and $17.1^{\circ}$ at $0.8 \mathrm{~ms}$ of injection under chamber pressure of $10 \mathrm{bar}$ and injection pressure of 600 bar. As another example, SUNME and SUNEE had respectively spray angles of $12.9^{\circ}$ and $12.7^{\circ}$ at $0.2 \mathrm{~ms}$ of injection under an injection pressure of $800 \mathrm{bar}$ and a chamber pressure of 5 bar. These similarities can be explained with the density, viscosity and contact angle values. The ethyl esters had larger viscosity values than the methyl esters nevertheless the methyl esters had bigger density and contact angle (and surface tension) values than the ethyl esters. These properties may have compensated each other and may have prevented differences in spray properties to occur. Moreover, the curves obtained for both ethyl esters and methyl esters were similar in macroscopic shape. One of the most important points was that effects of chamber pressure and injection pressure were similar for the two kinds of fuels. This may be because methyl esters and ethyl esters are the same in terms of the feedstock and production method thus, they are not physically completely different. Indeed, there were no huge distinctions in viscosity, contact angle and density values despite differences as explained in Section 2.2.

Sauter mean diameter (SMD) was calculated to estimate the microscopic spray characteristics of ethyl esters in comparison to those of methyl esters and fossil diesel. SMD is the average particle size of fuel droplets and can be calculated using the following correlation [47]:

$\mathrm{SMD}=6156 v^{0.385} \sigma^{0.737} \rho_{f}^{0.737} \rho_{a}^{0.06} \Delta P^{-0.54}$

where $\nu$ is the kinematic viscosity of a fuel, $\sigma$ is the surface tension of fuel, $\rho_{\mathrm{f}}$ is fuel density, $\rho_{\mathrm{a}}$ is the air density and $\Delta \mathrm{P}$ is the pressure difference between the injection pressure and the ambient pressure.
Table 7 Surface tension values found in the literature

\begin{tabular}{llll}
\hline Reference & $\begin{array}{l}\text { Surface tension } \\
\text { of diesel }(\mathrm{mN} / \mathrm{m})\end{array}$ & $\begin{array}{l}\text { Surface tension } \\
\text { of biodiesel } \\
(\mathrm{mN} / \mathrm{m})\end{array}$ & $\begin{array}{l}\text { Origin of } \\
\text { biodiesel }\end{array}$ \\
\hline$[39]$ & 27.3 & 35.2 & $\begin{array}{c}\text { Waste cooking } \\
\text { oil }\end{array}$ \\
{$[53]$} & 26.7 & 30.7 & $\begin{array}{l}\text { Jatropha oil } \\
\text { Castor oil }\end{array}$ \\
{$[70]$} & 25.45 & 31.83 & Palm oil \\
{$[47]$} & 25.5 & 26.2 & Karanja oil \\
{$[71]$} & 23 & 28 & Waste cooking \\
oil \\
{$[48]$} & 30.3 & 34.7 & Soybean oil \\
& & 31.2 & Palm oil \\
{$[60]$} & 29.2 & 32.6 & Drainage oil \\
{$[49]$} & 30.6 & 32.4 & \\
{$[44]$} & 29.5 & $\mathbf{3 1 . 4 3}$ & \\
Mean values & $\mathbf{2 7 . 5 1}$ & &
\end{tabular}

The correlation contains surface tension term. In this work, the surface tension of test fuels could not be measured, but a calculation was performed by using values available in the literature. Table 7 shows the surface tension values for both biodiesel and fossil-based diesel fuels obtained from the existing literature work. The estimation was performed by taking the mean of the reported values. The margin of error was calculated by considering the maximum and minimum surface tension values and the possible range for the SMD values was estimated accordingly.

Figure 10 shows the estimated SMD values for all test fuels under all experimental conditions. Injection and ambient pressures are effective parameters on SMD. As seen in the figure, SMD decreased as the injection pressure increased, and increased as the ambient pressure increased. This is consistent with the literature data [66, 67]. Biodiesel fuels had, on average, around 47\% higher SMD values than that of fossil-based diesel. Besides, ethyl esters had approximately $4 \%$ larger SMD values than methyl ester counterparts under the assumed surface tension value. However, contact angle values of ethyl esters were $2.6 \%$ lower than those of methyl esters, meaning that the surface tension effects of ethyl esters were slightly lower than those of the methyl esters. Considering this, the real difference in SMD values of methyl esters and ethyl esters could be less than $4 \%$.

\section{Conclusions}

The aim of the study was to investigate the spray characteristics of ethyl ester-type biodiesel fuels and to compare them with those of methyl esters and fossil-based diesel fuel. Experiments were conducted in a constant volume chamber under various injection pressures (600 and 800 bar) and various ambient pressures $(0,5,10$ and 15 bar). The 
Fig. 10 Estimation of SMD under all experimental conditions

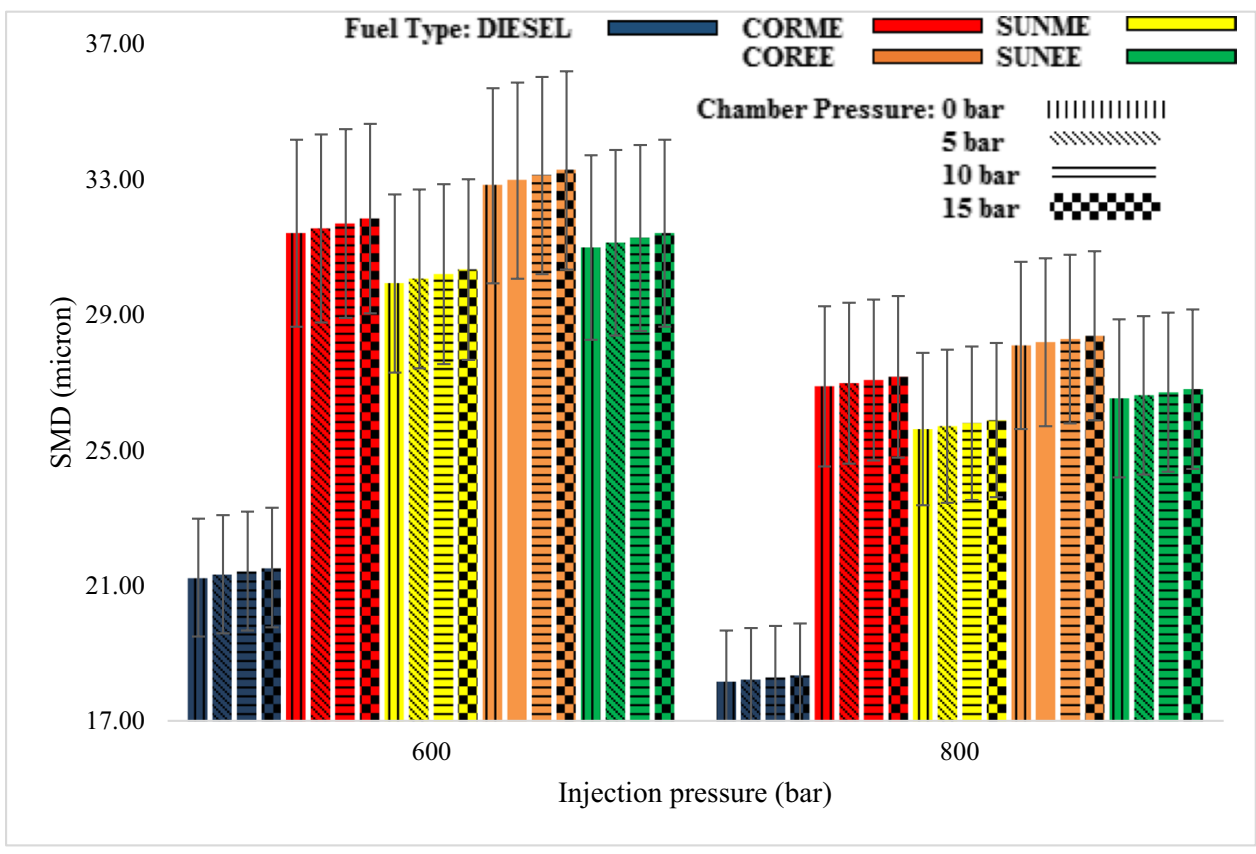

shadowgraph method was utilized as the optical technique to visualize the spray process.

The physical properties of the fuels had a direct effect on spray characteristics. On average, ethyl esters performed 2.8-20.2\% deeper penetrations and 5.1-19\% narrower spray angles than conventional diesel fuel under chamber pressures of 5 and 10 bar. In addition, SMD values of ethyl esters were around $48 \%$ higher than diesel on average. Higher density, viscosity and contact angle values of ethyl esters led to poorer atomization and increased spray momentum. In contrast, the macroscopic spray characteristics of ethyl esters were very similar to those of reference diesel fuel at the ambient pressure of 15 bar. On average, the distinctions were under $2 \%$. Considering the uncertainty and repeatability values, which were respectively $\pm 0.84 \%$ and $\pm 5 \%$, the difference was not significant.

Ethyl esters performed similar spray penetrations and angles with methyl esters. The difference between the fuels in terms of spray parameters were in the range of $1-3 \%$ for all test conditions. Besides, average SMD values of ethyl esters were lower than $4 \%$ compared to those of methyl esters considering all the test conditions. When taking the uncertainty and repeatability values into account, it could be stated that ethyl esters performed approximate results to methyl esters in terms of spray characteristics. This may be explained by considering density, viscosity and contact angle values. Ethyl esters had higher viscosity values on the contrary they had smaller density and contact angle values. These properties may have compensated each other thus similar spray characteristics may have been observed.

This study revealed that the spray characteristics of ethyl esters were very similar to those of methyl esters. As a result, the use of ethanol instead of methanol in biodiesel production cannot be considered a major drawback for diesel engines. Therefore, ethyl esters could have the potential of being used instead of methyl esters in diesel engines with no or small modifications. This will lead to the utilization of completely renewable biodiesels with improved cold weather performances.

Acknowledgements The authors are thankful to Prof. Dr. Erol Şeker and the members of Renewable Energy and Hydrogen Research Laboratory at İzmir Institute of Technology for providing the necessary equipment for biodiesel production. The authors would also like to thank Prof. Dr. Metin Tanoğlu and the members of the Composite Research Laboratory at İzmir Institute of Technology for the measurement of viscosity and surface tension values of fuels. We acknowledge Prof. Dr. Mustafa Güden and Prof. Dr. Alper Taşdemirci for providing the high-speed camera for the experiments.

Data availability The datasets generated during and/or analysed during the current study are not publicly available due to confidentiality but are available from the corresponding author on reasonable request.

\section{Declarations}

Conflict of interest The authors declare no competing interests.

\section{References}

1. Apicella B et al (2020) Effect of after-treatment systems on particulate matter emissions in diesel engine exhaust. Exp Thermal Fluid Sci 116(March):110107. https://doi.org/10.1016/j.expth ermflusci.2020.110107

2. Patel C et al (2019) Comparative compression ignition engine performance, combustion, and emission characteristics, and trace metals in particulates from Waste cooking oil, Jatropha 
and Karanja oil derived biodiesels. Fuel 236:1366-1376. https:// doi.org/10.1016/j.fuel.2018.08.137

3. Singh NK, Singh Y, Sharma A, Chinnasamy V, and Palamanit A, 2021"Rheological characteristics and tribological performance of neem biodiesel-based nano oil added with MWCNT," Biomass Convers. Biorefinery, pp. 1-11. doi: https://doi.org/10. 1007/s13399-021-01919-7.

4. Shrivastava P, Verma TN, Pugazhendhi A (2019) An experimental evaluation of engine performance and emisssion characteristics of CI engine operated with Roselle and Karanja biodiesel. Fuel 254:1-12. https://doi.org/10.1016/j.fuel.2019.115652

5. Ulu A, Çellek SB, Rodriguez AD, and Özkol Ü, (2019) "Experimental spray investigation of biodiesel fuels derived from corn oil and canola oil," in The Eurasia Proceedings of Science, Technology, Engineering \& Mathematics, vol. 7, pp. 346-356, [Online]. Available: https://dergipark.org.tr/tr/pub/epstem/issue/ 50288/656430. Accessed 7 Feb 2022

6. Nguyen T, Pham MH, Le Anh T (2020) Spray, combustion, performance and emission characteristics of a common rail diesel engine fueled by fish-oil biodiesel blends. Fuel 269:117108. https://doi.org/10.1016/j.fuel.2020.117108

7. Özçelik AE, Aydoğan H, Acaroğlu M (2015) Determining the performance, emission and combustion properties of camelina biodiesel blends. Energy Convers Manag 96:47-57. https://doi. org/10.1016/j.enconman.2015.02.024

8. Chen H, Su X, He J, Zhang P, Xu H, Zhou C (2021) Investigation on combustion characteristics of cyclopentanol/diesel fuel blends in an optical engine. Renew Energy 167:811-829. https://doi.org/10.1016/j.renene.2020.11.155

9. Magno A, Mancaruso E, Vaglieco BM (2016) Analysis of combustion phenomena and pollutant formation in a small compression ignition engine fuelled with blended and pure rapeseed methyl ester. Energy 106:618-630. https://doi.org/10.1016/j. energy.2016.03.106

10. Oumer AN, Hasan MM, Baheta AT, Mamat R, Abdullah AA (2018) Bio-based liquid fuels as a source of renewable energy: a review. Renew Sust Energ Rev 88:82-98. https://doi.org/10. 1016/j.rser.2018.02.022

11. Ulu A (2020) Experimental spray investigation of methyl ester and ethyl ester type biodiesel fuels in a constant volume combustion chamber. İzmir Institute of Technology, İzmir. https:// www.proquest.com/dissertations-theses/experimental-sprayinvestigation-methyl-ester/docview/2561443491/se-2?accou ntid=15253. Accessed 7 Feb 2022

12. "Statistical Review of World Energy 2020, (2020)" London. [Online]. Available: https://www.bp.com/content/dam/bp/busin ess-sites/en/global/corporate/pdfs/energy-economics/statisticalreview/bp-stats-review-2020-full-report.pdf. Accessed 7 Feb 2022

13. Tamilselvan P, Nallusamy N, Rajkumar S (2017) A comprehensive review on performance, combustion and emission characteristics of biodiesel fuelled diesel engines. Renew Sust Energ Rev 79:1134-1159. https://doi.org/10.1016/j.rser.2017.05.176

14. Razzak SA, Hossain MM, Lucky RA, Bassi AS, de Lasa H (2013) Integrated $\mathrm{CO} 2$ capture, wastewater treatment and biofuel production by microalgae culturing - a review. Renew Sust Energ Rev 27:622-653. https://doi.org/10.1016/j.rser.2013.05.063

15. Diger Kulaksiz B, Paluzar H (2021) Sunflower oil deodorizer distillate as novel feedstock for biodiesel production and its characterization as a fuel. Biomass Convers Biorefinery 0123456789:111. https://doi.org/10.1007/s13399-021-01596-6

16. Baskar G, Selvakumari IAE, Aiswarya R (2018) Biodiesel production from castor oil using heterogeneous $\mathrm{Ni}$ doped $\mathrm{ZnO}$ nanocatalyst. Bioresour Technol 250:793-798. https://doi.org/10.1016/j. biortech.2017.12.010

17. Turkkul B, Deliismail O, Seker E (2020) Ethyl esters biodiesel production from Spirulina sp. and Nannochloropsis oculata microalgal lipids over alumina-calcium oxide catalyst. Renew Energy 145:1014-1019. https://doi.org/10.1016/j.renene.2019. 06.093

18. Seraç MR, Aydın S, Yılmaz A, Şevik S (2020) Evaluation of comparative combustion, performance, and emission of soybean-based alternative biodiesel fuel blends in a CI engine. Renew Energy 148:1065-1073. https://doi.org/10.1016/j.renene.2019.10.090

19. Asokan MA, Prabu SS, Bade PKK, Nekkanti VM, Gutta SSG (2019) Performance, combustion and emission characteristics of juliflora biodiesel fuelled DI diesel engine. Energy 173:883-892. https://doi.org/10.1016/j.energy.2019.02.075

20. Yilbaşi Z, Yesilyurt MK, and Arslan M, (2021) "The production of methyl ester from industrial grade hemp (Cannabis sativa L.) seed oil: a perspective of Turkey - the optimization study using the Taguchi method," Biomass Convers. Biorefinery, pp. 1-21, doi: https://doi.org/10.1007/s13399-021-01751-z.

21. Maximo GJ et al (2018) Improving the cold flow behavior of methyl biodiesel by blending it with ethyl esters. Fuel 226:87-92. https://doi.org/10.1016/j.fuel.2018.03.154

22. Reyero I, Arzamendi G, Zabala S, Gandía LM (2015) Kinetics of the NaOH-catalyzed transesterification of sunflower oil with ethanol to produce biodiesel. Fuel Process Technol 129:147-155. https://doi.org/10.1016/j.fuproc.2014.09.008

23. Gui MM, Lee KT, Bhatia S (2009) Supercritical ethanol technology for the production of biodiesel: process optimization studies. J Supercrit Fluids 49(2):286-292. https://doi.org/10.1016/j.supflu. 2008.12.014

24. Outlook I (2021) Renewable Methanol. International Renewable Energy Agency, Abu Dhabi

25. "Global Ethanol Production," (2020). https://afdc.energy.gov/data/ 10331 (accessed Mar. 07, 2021).

26. “Transport Biofuels," (2020). https://www.iea.org/reports/renew ables-2020/transport-biofuels (accessed Mar. 07, 2021).

27. (2020) Biofuels. In: in OECD-FAO Agricultural Outlook 20202029. OECD Publishing, Rome, pp 196-209

28. Zanuttini MS, Pisarello ML, Querini CA (2014) Butia Yatay coconut oil: process development for biodiesel production and kinetics of esterification with ethanol. Energy Convers Manag 85:407-416. https://doi.org/10.1016/j.enconman.2014.05.080

29. Mendow G, Veizaga NS, Sánchez BS, Querini CA (2011) Biodiesel production by two-stage transesterification with ethanol. Bioresour Technol 102(22):10407-10413. https://doi.org/10. 1016/j.biortech.2011.08.052

30. Sanli H, Canakci M, Alptekin E, Turkcan A, Ozsezen AN (2015) Effects of waste frying oil based methyl and ethyl ester biodiesel fuels on the performance, combustion and emission characteristics of a DI diesel engine. Fuel 159:179-187. https://doi.org/10.1016/j. fuel.2015.06.081

31. Alptekin E, Sanli H, Canakci M (2019) Combustion and performance evaluation of a common rail DI diesel engine fueled with ethyl and methyl esters. Appl Therm Eng 149:180-191. https:// doi.org/10.1016/j.applthermaleng.2018.12.042

32. Gautam R, Kumar N, Sharma P (2013) Comparative assessment of performance, emission and combustion characteristics of blends of methyl and ethyl ester of jatropha oil and diesel in compression ignition engine. SAE Tech Pap 2013-01-2664. https://doi.org/10. 4271/2013-01-2664

33. Murugesan A, Subramaniam D, Vijayakumar C, Avinash A, Nedunchezhian N (2012) Analysis on performance, emission and combustion characteristics of diesel engine fueled with methylethyl esters. J Renew Sustain Energy 4:1-12. https://doi.org/10. $1063 / 1.4767911$

34. Gautam R, Kumar N, Pali HS, Kumar P (2016) Experimental studies on the use of methyl and ethyl esters as an extender in a small capacity diesel engine. Biofuels 7(6):637-646. https://doi. org/10.1080/17597269.2016.1187538 
35. da Silva MAV, Ferreira BLG, da Costa Marques LG, Murta ALS, de Freitas MAV (2017) Comparative study of NOx emissions of biodiesel-diesel blends from soybean, palm and waste frying oils using methyl and ethyl transesterification routes. Fuel 194:144156. https://doi.org/10.1016/j.fuel.2016.12.084

36. Singh N, Kumar H, Jha MK, Sarma AK (2015) Complete heat balance, performance, and emission evaluation of a CI engine fueled with Mesua ferrea methyl and ethyl ester's blends with petrodiesel. J Therm Anal Calorim 122:907-916. https://doi.org/ 10.1007/s10973-015-4777-8

37. Eliçin AK, Öztürk F, Baran MF, Esgici R (2019) The use of rapeseed oil methyl and ethyl esters and of rapeseed oil-diesel mixtures as fuels for diesel engine. Fresenius Environ Bull 28:7915-7923

38. Makareviciene V, Janulis P (2003) Environmental effect of rapeseed oil ethyl ester. Renew Energy 28(15):2395-2403. https://doi. org/10.1016/S0960-1481(03)00142-3

39. Yu S et al (2018) Experimental study on the diesel and biodiesel spray characteristics emerging from equilateral triangular orifice under real diesel engine operation conditions. Fuel 224:357-365. https://doi.org/10.1016/j.fuel.2018.03.099

40. Lee S, Lee CS, Park S, Gupta JG, Maurya RK, Agarwal AK (2017) Spray characteristics, engine performance and emissions analysis for Karanja biodiesel and its blends. Energy 119:138151. https://doi.org/10.1016/j.energy.2016.12.043

41. Mohan B, Yang W, Tay KL, Yu W (2014) Experimental study of spray characteristics of biodiesel derived from waste cooking oil. Energy Convers Manag 88:622-632. https://doi.org/10.1016/j. enconman.2014.09.013

42. Subramanian KA, Lahane S (2013) Comparative evaluations of injection and spray characteristics of a diesel engine using karanja biodiesel-diesel blends. Int J Energy Res 37(6):582-597. https:// doi.org/10.1002/er.1947

43. Deng J, Li C, Hu Z, Wu Z, Li L (2010) Spray characteristics of biodiesel and diesel fuels under high injection pressure with a common rail system. SAE Tech Pap 2010-01-2268. https://doi. org/10.4271/2010-01-2268

44. Xie H, Song L, Xie Y, Pi D, Shao C, Lin Q (2015) An experimental study on the macroscopic spray characteristics of biodiesel and diesel in a constant volume chamber. Energies 8(6):5952-5972. https://doi.org/10.3390/en8065952

45. Tinprabath P, Hespel C, Chanchaona S, Foucher F (2013) Influence of biodiesel and diesel fuel blends on the injection rate and spray injection in non-vaporizing conditions. SAE Tech Pap 201324-0032. https://doi.org/10.4271/2013-24-0032

46. Gupta JG, Agarwal AK (2016) Macroscopic and microscopic spray characteristics of diesel and Karanja Biodiesel Blends. SAE Tech Pap 2016-01-0869. https://doi.org/10.4271/2016-01-0869

47. Wang X, Huang Z, Kuti OA, Zhang W, Nishida K (2010) Experimental and analytical study on biodiesel and diesel spray characteristics under ultra-high injection pressure. Int J Heat Fluid Flow 31(4):659-666. https://doi.org/10.1016/j.ijheatfluidflow.2010.03. 006

48. Chen P-C, Wang W-C, Roberts WL, Fang T (2013) Spray and atomization of diesel fuel and its alternatives from a single-hole injector using a common rail fuel injection system. Fuel 103:850 861. https://doi.org/10.1016/j.fuel.2012.08.013

49. Kuti OA, Zhu J, Nishida K, Wang X, Huang Z (2013) Characterization of spray and combustion processes of biodiesel fuel injected by diesel engine common rail system. Fuel 104:838-846. https://doi.org/10.1016/j.fuel.2012.05.014

50. Agarwal AK, Som S, Shukla PC, Goyal H, Longman D (2015) Innozzle flow and spray characteristics for mineral diesel, Karanja, and Jatropha biodiesels. Appl Energy 156:138-148. https://doi. org/10.1016/j.apenergy.2015.07.003
51. Mancaruso E, Perozziello C, Sequino L, Vaglieco BM (2019) Characterization of pure and blended biodiesel spray in a compression ignition engine by means of advanced diagnostics and 1D model. Fuel 239:1102-1114. https://doi.org/10.1016/j.fuel.2018. 11.099

52. Hwang J, Bae C, Patel C, Agarwal AK, Gupta T (2016) An experimental investigation on spray characteristics of waste cooking oil, jatropha, and karanja biodiesels in a constant volume combustion chamber. SAE Tech Pap 2016-01-2263. https://doi.org/10.4271/ 2016-01-2263

53. Patel C, Lee S, Tiwari N, Agarwal AK, Lee CS, Park S (2016) Spray characterization, combustion, noise and vibrations investigations of Jatropha biodiesel fuelled genset engine. Fuel 185:410 420. https://doi.org/10.1016/j.fuel.2016.08.003

54. Schuchardt U, Sercheli R, Vargas RM (1998) Transesterification of vegetable oils : a review. J Braz Chem Soc 9(1):199-210. https://doi.org/10.1590/S0103-50531998000300002

55. Ghanei R, Moradi GR, TaherpourKalantari R, Arjmandzadeh E (2011) Variation of physical properties during transesterification of sunflower oil to biodiesel as an approach to predict reaction progress. Fuel Process Technol 92(8):1593-1598. https://doi.org/ 10.1016/j.fuproc.2011.04.003

56. "Shell V-Power Diesel," (2019) Shell. pp. 1-20, [Online]. Available: https://www.epc.shell.com/documentRetrieve.asp?docum entId=97483798. Accessed 7 Feb 2022

57. Puhan S, Vedaraman N, Sankaranarayanan G, Ram BVB (2005) Performance and emission study of Mahua oil (madhuca indica oil) ethyl ester in a 4-stroke natural aspirated direct injection diesel engine. Renew Energy 30(8):1269-1278. https://doi.org/10. 1016/j.renene.2004.09.010

58. Figliola RS and Beasley DE, (2011) Theory and design for mechanical measurements, 5th ed. John Wiley \& Sons, Inc.

59. Sathiyamoorthi R, Sankaranarayanan G, Munuswamy DB, and Devarajan Y, (2021) "Experimental study of spray analysis for Palmarosa biodiesel-diesel blends in a constant volume chamber," Environ Prog Sustain Energy, no. April, pp. 1-10, doi: https://doi. org/10.1002/ep.13696.

60. Fu W, Li F, Meng K, Liu Y, Lin Q (2020) Experimental and analysis of macroscopic spray characteristics of biodiesel blended with Di-n-butyl ether under inert conditions. Waste Biomass Valorization 11(7):3501-3511. https://doi.org/10.1007/ s12649-019-00689-8

61. “ImageJ Download.” https://imagej.nih.gov/ij/download.html (accessed Oct. 26, 2020).

62. Gonzalez RC and Woods RE, Digital image processing, 3rd ed. Pearson Education International.

63. He C, Ge Y, Tan J, Han X (2008) Spray properties of alternative fuels: a comparative analysis of biodiesel and diesel. Int J Energy Res 32(14):1329-1338. https://doi.org/10.1002/er.1440

64. Heywood JB, (1988) Internal combustion engine fundamentals, 1st ed. McGraw-Hill, Inc.

65. Baumgarten C (2006) Mixture formation in internal combustion engines, 1st edn. Springer-Verlag, Berlin Heidelberg

66. Yadav PS and Gautam R, (2021) "Numerical and experimental analysis on spray characteristics of biodiesel (waste cooking oil) using pressure swirl atomizer," Environ Prog Sustain Energy, pp. 1-13, doi: https://doi.org/10.1002/ep.13761.

67. Yadav P, Kumar N, and Gautam R, (2021) "Improvement in performance of $\mathrm{CI}$ engine using various techniques with alternative fuel," Energy Sources, Part A Recover. Util. Environ Eff, pp. 1-27, doi: https://doi.org/10.1080/15567036.2020.1864517.

68. Tian J et al (2021) Experimental study on spray characteristics of octanol biodiesel and modification of spray tip penetration model. Phys Fluids 33:1-14. https://doi.org/10.1063/5.0063572

69. Tian J et al (2022) Experimental study on the spray characteristics of octanol diesel and prediction of spray tip penetration by ANN 
model. Energy 239:1-15. https://doi.org/10.1016/j.energy.2021. 121920

70. Das M, Sarkar M, Datta A, Santra AK (2018) An experimental study on the combustion, performance and emission characteristics of a diesel engine fuelled with diesel-castor oil biodiesel blends. Renew Energy 119:174-184. https://doi.org/10.1016/j. renene.2017.12.014
71. Lahane S, Subramanian KA (2015) Effect of different percentages of biodiesel-diesel blends on injection, spray, combustion, performance, and emission characteristics of a diesel engine. Fuel 139:537-545. https://doi.org/10.1016/j.fuel.2014.09.036

Publisher's Note Springer Nature remains neutral with regard to jurisdictional claims in published maps and institutional affiliations. 